\title{
Characterization of Sacral Interneurons That Mediate Activation of Locomotor Pattern Generators by Sacrocaudal Afferent Input
}

\author{
Alex Etlin, ${ }^{1}$ Eran Finkel, ${ }^{1 \dagger}$ Yoav Mor, ${ }^{1}$ Michael J. 0'Donovan, ${ }^{2}$ Lili Anglister, ${ }^{1}$ and Aharon Lev-Tov ${ }^{1}$ \\ ${ }^{1}$ Department of Medical Neuroscience, Institute for Medical Research Israel-Canada, Hebrew University-Hadassah Medical School, Jerusalem 91120, Israel, \\ and ${ }^{2}$ Section of Developmental Neurobiology, National Institute of Neurological Disorders and Stroke, National Institutes of Health, Bethesda, Maryland \\ 20892
}

Identification of the neural pathways involved in retraining the spinal central pattern generators (CPGs) by afferent input in the absence of descending supraspinal control is feasible in isolated rodent spinal cords where the locomotor CPGs are potently activated by sacrocaudal afferent (SCA) input. Here we study the involvement of sacral neurons projecting rostrally through the ventral funiculi (VF) in activation of the CPGs by sensory stimulation. Fluorescent labeling and immunostaining showed that VF neurons are innervated by primary afferents immunoreactive for vesicular glutamate transporters 1 and 2 and by intraspinal neurons. Calcium imaging revealed that $55 \%$ of the VF neurons were activated by SCA stimulation. The activity of VF neurons and the sacral and lumbar CPGs was abolished when non-NMDA receptors in the sacral segments were blocked by the antagonist CNQX. When sacral NMDA receptors were blocked by APV, the sacral CPGs were suppressed, VF neurons with nonrhythmic activity were recruited and a moderate-drive locomotor rhythm developed during SCA stimulation. In contrast, when the sacral CPGs were activated by SCA stimulation, rhythmic and nonrhythmic VF neurons were recruited and the locomotor rhythm was most powerful. The activity of 73 and $27 \%$ of the rhythmic VF neurons was in-phase with the ipsilateral and contralateral motor output, respectively. Collectively, our studies indicate that sacral VF neurons serve as a major link between SCA and the hindlimb CPGs and that the ability of SCA to induce stepping can be enhanced by the sacral CPGs. The nature of the ascending drive to lumbar CPGs, the identity of subpopulations of VF neurons, and their potential role in activating the locomotor rhythm are discussed.

\section{Introduction}

The locomotor central pattern generators (CPGs) are known to produce the rhythmic patterned output required for stepping (Gelfand et al., 1988; Rossignol et al., 1996; Arshavsky et al., 1997; Hultborn et al., 1998; Kiehn, 2006; Lev-Tov and O'Donovan, 2009). The CPGs are controlled by descending supraspinal commands; however, they can be activated in the absence of descending control in spinal cord injury (SCI) patients and spinalized animals, by afferent-input from load and joint receptors (Grillner and Rossignol, 1978; Grillner and Zanger, 1979; Duysens and Pearson, 1980; Pearson, 2004; Prochazka et al., 1997; Dietz and Duysens, 2000; Dietz et al., 2002). The ability of input from load and joint receptors to retrain the locomotor CPGs and improve

\footnotetext{
Received Sept. 13, 2012; revised 0ct. 18, 2012; accepted Nov. 6, 2012.

Author contributions: M.J.O., L.A., and A.L.-T. designed research; A.E., E.F., and A.L.-T. performed research; Y.M. contributed unpublished reagents/analytic tools; A.E., E.F., Y.M., and A.L.-T. analyzed data; M.J.O., L.A., and A.L.-T. wrote the paper.

This work was supported by the Israel Science Foundation Grants 129/04, 1591/08, 1930/08 to A.L.-T. and the United States-Israel Binational Science Foundation Grants 2001010 and 2005020 to A.L.-T. and M.J.O.

The authors declare no competing financial interests.

${ }^{\dagger}$ Deceased, March 2012.

Correspondence should be addressed to Dr. Aharon Lev-Tov, Department of Medical Neurobiology, Hebrew University Medical School, Jerusalem, 91010, Israel. E-mail: aharonl@ekmd.huji.ac.il.

DOI:10.1523/JNEUROSCI.4390-12.2013

Copyright $\odot 2013$ the authors $\quad 0270-6474 / 13 / 330734-14 \$ 15.00 / 0$
}

motor function in humans with SCI (Dietz et al., 1997; Dietz, 2009; Edgerton et al., 2006; 2008; Wernig et al., 1998) raises questions about the functional organization of the mediating pathways and the possibility of other sensory modalities to reactivate the CPGs. Our finding that stimulation of nociceptive and nonnociceptive sacrocaudal afferents (SCAs) has an extraordinary capacity to activate the CPGs in isolated spinal cords of neonatal rats (Lev-Tov et al., 2000; Strauss and Lev-Tov, 2003; Blivis et al., 2007; also see Klein and Tresch, 2010; for rat; and Mandadi and Whelan, 2009; for mouse) provided us not only with an additional potent means for activating the CPGs, but also with an experimentally accessible model to study the neuronal circuitry linking the SCA and CPGs and their mechanism of action. Using this model, we showed that activation of the CPGs by SCA stimulation required glutamatergic synaptic excitation (Strauss and Lev-Tov, 2003) of heterogeneous groups of sacral neurons with crossed and uncrossed ascending projections through the ventral (VF) and lateral white matter funiculi (Etlin et al., 2010; Lev-Tov et al., 2010). Although a basic knowledge of the lumbar projections and functional organization of these sacral relay neurons is available from our lesion and fluorescent labeling experiments (Etlin et al., 2010; Lev-Tov et al., 2010), direct evidence of their involvement in sensory activation of the hindlimb CPGs is still missing. Thus, it is still unknown whether commissural VF neurons, which have been suggested to contribute more substantially 
A

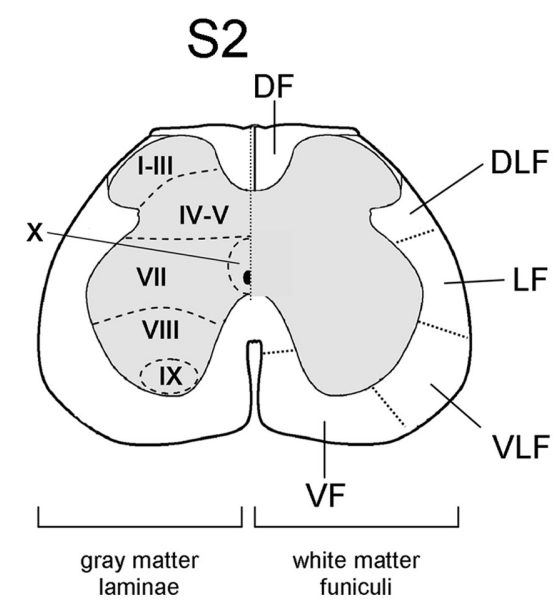

B

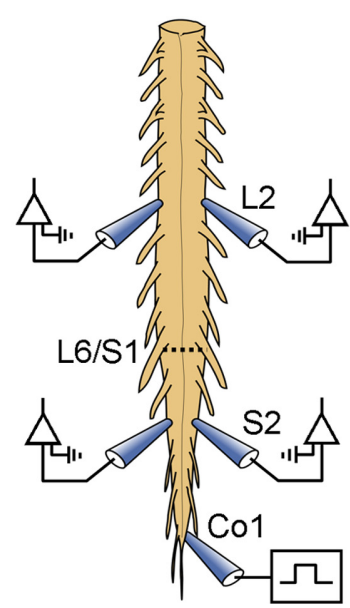

C

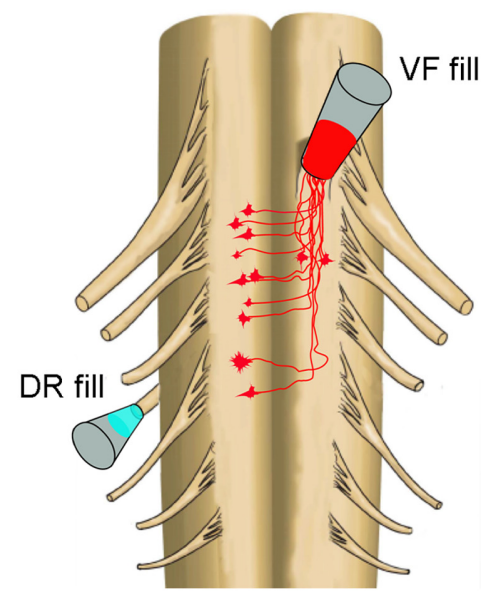

Figure 1. Studies of sacral neurons with rostral projections through the VF. $A$, Schematic cross section through the S2 segment of the spinal cord. VF, VLF, LF, DLF, and DF are ventral, ventrolateral, lateral, dorsolateral, and dorsal funiculi, respectively. $\boldsymbol{B}$, Illustration of the isolated en bloc spinal cord preparation is shown with the recording electrodes from the left and right $\$ 2$ and $L 2$ ventral roots. The first coccygeal dorsal root (CO1) is stimulated to produce the rhythm. A hyphenated line indicates the lumbosacral junction (L6-S1). C, Primary afferent innervation of VF neurons. Retrograde labeling of VF neurons through cut VF axon bundles at the lumbosacral or the S1-S2 junction (red) and anterograde labeling of contralateral afferents entering the sacral cord through the S3 dorsal root (cyan) by different fluorophores. The en bloc spinal cord preparation is shown with ventral side up. Vibratome cross sections of the fixed preparation were immunostained for VGluT1 or VGluT2 to determine a possible glutamatergic innervation of VF neurons by SCA, as described in Figures 2, 3, and 4.

than other sacral proprioneurons to activation of the CPGs (Etlin et al., 2010; Lev-Tov et al., 2010), are innervated by glutamatergic SCA, whether VF neurons are activated by SCA stimulation, and if so, what the relation is between their activity and the concomitant motor output. Here we address these questions by a combined approach, using confocal imaging of fluorescently labeled SCA and sacral VF neurons and immunostaining for vesicular glutamate transporters (VGluTs), calcium imaging of VF neurons with concurrent electrophysiological recordings of the motor output during SCA stimulation, and Wavelet transformation-based analyses of the correlation between the imaging and electrophysiological data in the time/frequency domain. We show that sacral VF neurons are innervated by glutamatergic primary afferents and intraspinal neurons, that rhythmic and nonrhythmic VF neurons are activated by SCA stimulation, that the activated VF neurons contribute to activation of hindlimb CPGs, and that the capacity of SCA to induce stepping is modulated by the sacral-CPGs.

\section{Materials and Methods}

All procedures were approved by and performed according to the guidelines of The Hebrew University Ethics Committee. The Hebrew University is an Association for Assessment and Accreditation of Laboratory Animal Care internationally accredited institute. The experiments were performed on newborn Sprague Dawley rats ordered from the University's official supplier (Harlan Laboratories) on the day of the experiment.

Preparations. Spinal cords (T6-Co3) were isolated from P1-P3 isoflurane-anesthetized male or female rats (Lev-Tov and Delvolvé, 2000; Lev-Tov et al., 2000; Delvolvé et al., 2001; Blivis et al., 2007). Preparations were transferred to a recording chamber and superfused continuously with an oxygenated artificial CSF (Kremer and Lev-Tov, 1997; Lev-Tov et al., 2000; Delvolvé et al., 2001; Blivis et al., 2007).

Stimulation and recordings. Suction electrode recordings were obtained from pairs of lumbar and sacral ventral roots using a high-gain DC or $0.1 \mathrm{~Hz}$ to $10 \mathrm{kHz}$ AC amplifier (Fig. $1 B$ ).

Rhythmic activity. Rhythmic activity was induced by graded electrical stimulation of SCAs traveling mainly in the first coccygeal dorsal root $(\mathrm{Co} 1)$ (Fig. 1B). The threshold (T) was measured from the polysynaptic response produced by single pulse stimulation in the ipsilaterally re- corded S2 and L2 ventral roots (Etlin et al., 2010). In some of the experiments, the incoming afferent volleys were recorded from the proximal region of the stimulated dorsal root to monitor the stimulus intensity required for activation of Group I-II and A $\delta$ afferents (see Fig. $5 A$ ). When required, the experimental bath was divided into two compartments by a Vaseline wall to test regionally dependent effects of various drugs (see Figs. 9, 10A). The drugs used in this work were the non-NMDA receptor blocker CNQX, and the NMDA receptor blocker APV (Sigma Aldrich).

Fluorescent labeling and immunostaining. Sacral VF neurons were labeled by loading fluorescent dextran (Invitrogen) into axon bundles peeled away from the VF (see Fig. $1 A, C$ ) at the S1-S2 (or lumbosacral, L6-S1 as specified) junction and drawn into a suction electrode containing $\sim 20 \% \mathrm{w} / \mathrm{v}$ of the dye dissolved in distilled water with or without $0.2 \%$ Triton X-100 detergent for 16-24 h (O'Donovan et al., 1993; Etlin et al., 2010). Sacrocaudal afferents were labeled by loading a different fluorescent dextran through the cut contralateral S3 dorsal roots (see Fig. 1C). Combinations of three fluorescent dextrans (Texas red, fluorescein green, or Cascade blue) were used as specified in the experiment. Isolated spinal cords were then fixed in 4\% paraformaldehyde (in PBS) for 4-10 $\mathrm{h}$ at $4^{\circ} \mathrm{C}$, subsequently embedded in warm $5 \%$ agar (in PBS), and 50 - to $100-\mu \mathrm{m}$ sections were cut with a Vibratome. Sections were collected in wells (free-floating technique) and processed for morphological analysis or immunolabeling (Mentis et al., 2005; Finkel et al., 2011; Etlin et al., 2012; Mor et al., 2012). Glutamatergic contacts were detected using antibodies against the vesicular glutamate transporters (VGluT1 and 2; Synaptic Systems) incubated in BSA and Triton at $4^{\circ} \mathrm{C}$ for $24 \mathrm{~h}$. Immunoreactive (IR) sites were revealed by the binding of secondary antibodies conjugated to a specific fluorochrome (Jackson Immunoresearch Laboratories). Images were obtained using a confocal microscope (Fluoview, 1000 Olympus) equipped with 3 single photon lasers.

Imaging of sacral VF neuron activity with calcium-sensitive dyes. A detailed account of retrograde labeling with calcium fluorescent indicators and the visualization techniques can be found (O'Donovan et al., 1993,1994; Lev-Tov and O’Donovan, 1995; Bonnot et al., 2002, 2005). Briefly, sacral VF neurons were retrogradely labeled by soaking narrow strips of cut VF axon bundles at the lumbosacral junction with $25-50 \mathrm{~mm}$ calcium-green-dextran (Invitrogen) applied through a tightly fitting suction electrode. After $12-16 \mathrm{~h}$ of loading, the cord was mounted in a chamber equipped for electrophysiological recording and viewed at the caudal S1 and the entire S2 segment through the ventral (in most of the 
cases), lateral (preparations rotated with lateral side up) and dorsal aspects (preparations mounted with dorsal side up after removing parts of the dorsal horn, in few experiments), using epifluorescence microscopy (BX51WI, Olympus) and imaged with a cooled 14bit CCD camera (EXI Aqua, QImaging). Labeled VF neurons were visualized using a waterimmersed $\times 20$ objective (NA 0.5 ), and their location was defined with respect to the dye injection site and distance from midline. The depth of the imaged neurons was estimated by the distance of the focal plane from the outer surface. Fluorophores were excited at the appropriate wavelength, and images were acquired at 25-30 fps during neural activity induced by SCA stimulation and stored on the computer's hard disk using the Q Capture Pro software. The imaging and electrophysiological data were synchronized using TTL pulses applied to initiate the electrophysiological data acquisition, open the shutter of the camera, start the image acquisition, trigger the stimulus trains, and finally close the shutter (for further details, see Fig. 6 and related text in Results).

Data acquisition and analyses. Electrophysiological data were digitized (Digidata 1320A, Molecular Devices) and stored on the computer's hard disk for subsequent analyses (Gabbay et al., 2002; Strauss and Lev-Tov, 2003; Gabbay and Lev-Tov, 2004; Etlin et al., 2010). All our electrophysiological and imaging data were analyzed using "Spinalcore," a menudriven MATLAB-based program for electrophysiological and imaging signal-processing and for stationary and nonstationary time series analyses, developed by Mor and Lev-Tov (2007). To speed up the time consuming calculations of the analyses, we exploited graphic processing unit-based parallel processing using the NVIDIA developed Compute Unified Device Architecture (Mor et al., 2011, 2012). Wavelet and Wavelet coherence analyses were performed to detect rhythmicity, determine the phase/power between the recorded time series in time/frequency domain (Mor and Lev-Tov, 2007; Etlin et al., 2010), and examine the relation between the activity pattern of the imaged VF neurons and the concurrent motor output during SCA stimulation (see the detailed description in Fig. 6 and related text in Results).

The statistical significance of the normalized parameters of the rhythm (i.e., frequency, power, and coherence) extracted from WT analyses was tested using conventional methods for multiple comparisons of means in linear statistics (factorial ANOVA and post hoc tests) (Etlin et al., 2010), whereas the statistical significance of the phase data were examined using circular statistics procedures for directionality (Rayleigh's test) (Zar, 1999) and multiple comparisons (Watson-Williams test) (Zar, 1999).

\section{Results}

\section{Glutamatergic innervation of sacral VF neurons}

Activation of the locomotor CPGs by SCA stimulation required glutamatergic synaptic excitation (Strauss and Lev-Tov, 2003) of heterogeneous groups of sacral neurons with crossed and uncrossed ascending projections through the VF and lateral white matter funiculi (Etlin et al., 2011; Lev-Tov et al., 2010). Because sacral neurons with rostral VF projections provide the most prominent contribution to the generation of the rhythm (Etlin et al., 2010), the first part of our study was aimed to determine whether the sacral VF neurons are innervated by sacrocaudal glutamatergic input. Accordingly, we established whether sacral VF neurons with lumbar projections, receive sacrocaudal afferent innervation and whether the putative contacts between them express immunoreactivity (IR) for VGluTs. Figure 2 shows confocal projected images of cross sections through the second sacral segment after retrograde labeling of cut VF axon bundles at the lumbosacral junction with fluorescent dextran, anterograde labeling of the contralateral sacrocaudal afferents entering the S3 dorsal root with another fluorescent dextran, and immunostaining for VGluT1 (Fig. 2A,C,D). The high-power confocal micrographs of a single optical slice, shown in Figure $2 E$, demonstrate that the afferent terminals (cyan) contacting VF sacral neurons (red) express VGluT1 IR (yellow; Fig. 2F; see also Fig. 4A, in different colors). Thus, some of the sacral VF neurons appear to be innervated directly by VGluT1 ${ }^{+}$afferent terminals. Analyses of 375 S2 VF neurons with crossed rostral projections in two different experiments revealed that $17.8 \%$ of them were contacted directly by VGluT $1{ }^{+}$terminal boutons of sacral afferents entering the cord through the S3-S2 dorsal root ipsilateral to their somata. The laminar distribution of S2 VF neurons innervated by S2-S3 afferent terminals with VGluT1 IR in this series of experiments $(n=2)$ is summarized in Table 1 (left).

A similar approach was taken to study possible VGluT2 ${ }^{+}$innervation of sacral VF neurons (Figs. 3, 4B). Confocal imaging of cross sections through the S2 segment of the spinal cord after double labeling of VF neurons and sacral afferents (Fig. 3C) followed by immunostaining for VGluT2 (Fig. 3D) revealed that some of the VF neurons located mainly in the deep dorsal and intermediate gray matter laminae of S2 received VGluT2 ${ }^{+}$innervation from afferents entering the cord via the $\mathrm{S} 3$ dorsal root (Figs. 3C,E, 4B). However, the majority of the VGluT2 ${ }^{+}$synaptic boutons on VF neurons were not associated with sacral afferents (Fig. 3F) (Todd et al., 2003; Alvarez et al., 2004; Persson et al., 2006). The laminar distribution of VF neurons with crossed rostral projections that are innervated by VGluT2 ${ }^{+}$terminal afferents entering via the $\mathrm{S} 2-\mathrm{S} 3$ dorsal roots in 4 different experiments is summarized in Table 1 (right).

In summary, the results described in this section suggest that some of the rostrally projecting VF neurons are most likely innervated by Group I and II proprioceptive afferents (VGluT1positive Figs. 2 and 4), some may also be contacted by nociceptive primary afferents (VGluT2-positive afferent contacts, Figs. 3, 4) (Todd et al., 2003; Alvarez et al., 2004; Persson et al., 2006) and many others by intraspinal neurons (VGluT2-positive but lacking afferent contacts, Fig. $3 F$ ).

\section{The involvement of high- and low-threshold afferents in activation of the rhythm}

Our previous studies have shown that mechanical and radiant heat stimulation of sacrocaudal dermatomes could induce locomotor-like activity in the neonatal rat spinal cord (Blivis et al., 2007), and the stimulus intensity required to induce the rhythm by electrical SCA stimulation activates both low- and higher-threshold sacral afferents (Delvolvé et al., 2001; Blivis et al., 2007). We next determined whether the low-threshold afferents, which cannot produce the rhythm by themselves, contribute to activation of the rhythm by higher-threshold afferents. To accomplish this, we divided the first coccygeal dorsal root (Co1) into two branches and examined the effects of low-intensity stimulation of one branch at Group I, II strength on the rhythm generated by high-intensity graded stimulation (Group I, II, and A $\delta$ strength) of the other branch.

The afferent volleys produced during the stimulus trains were monitored using en passant suction electrode recordings from the undivided proximal region of the Col dorsal root, and the motor output was recorded from the left and right S2 and L2 ventral roots (Fig. 5A). Figure 5 shows that low-intensity stimulation of branch I, which elicited short latency proprioceptive afferent volley (red) in the dorsal root, failed to produce the rhythm (Fig. $5 B$, Br. I). Concurrent low-intensity stimulation of both branches (data not shown) also failed to produce the rhythm. However, stimulation of branch II at higher intensity elicited both fast and much slower afferent volleys in the stimulated dorsal root (blue) and elicited the rhythm (Fig. 5B, Br. II).

Next, we showed that the rhythm produced by high intensity stimulation of branch II could be enhanced by low intensity stimulation of fast conducting afferents in branch I (Fig. 5B, Br I + II). 

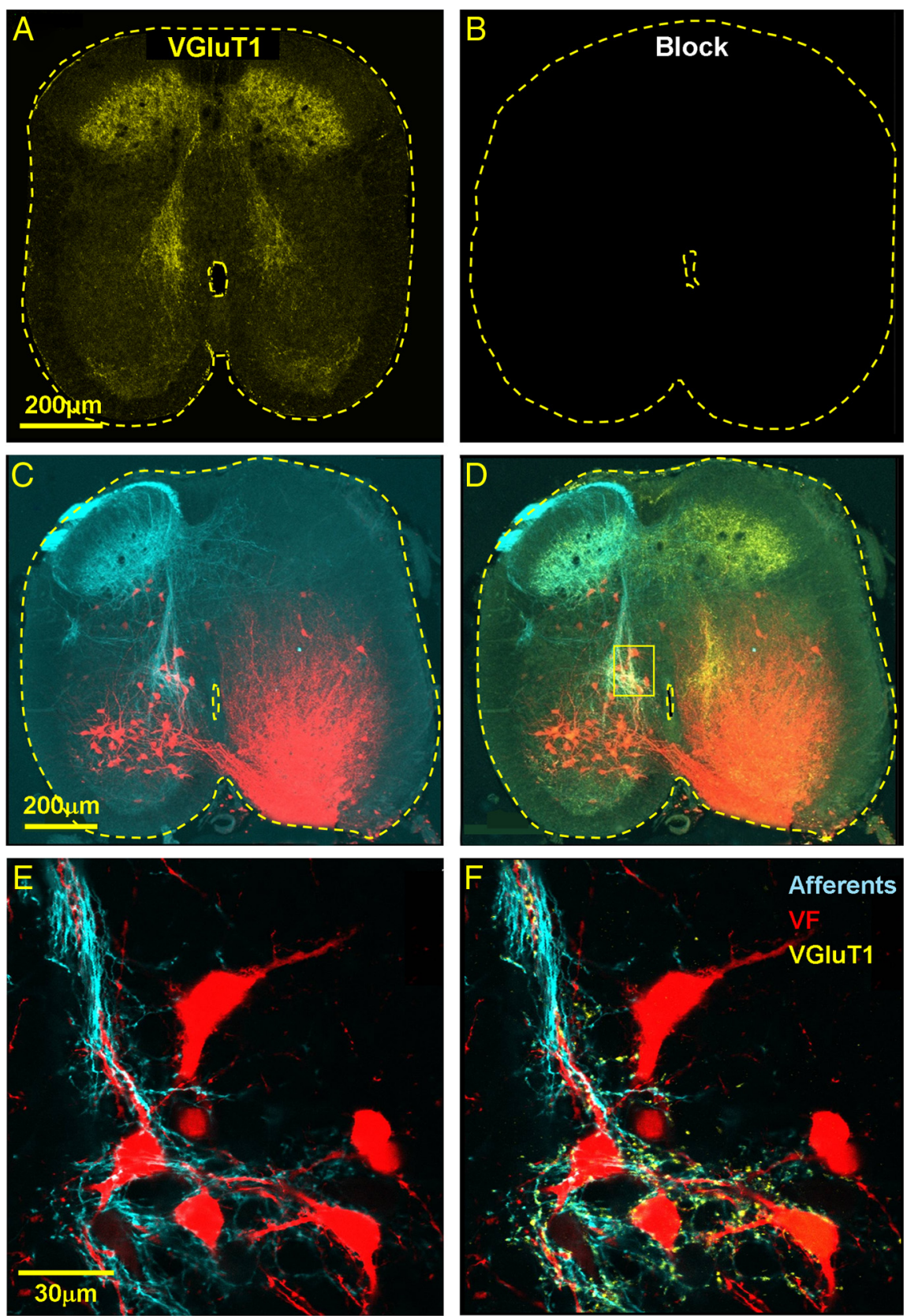

Figure 2. Primary afferent VGluT1-immunoreactive innervation of VF neurons. $\boldsymbol{A}, \boldsymbol{B}$, The confocal micrograph in $\boldsymbol{A}$ demonstrates specific immunostaining for VGluT1 (yellow) in a cross section through the $\mathrm{S} 2$ segment, which is completely eliminated by pretreatment with the blocking peptide of the primary VGluT1 antibodies $(\boldsymbol{B})$. C, Low-power projected confocal micrographs of a $50-\mu \mathrm{m}$ cross section cut through the $S 2$ segment of the spinal cord shows VF neurons retrogradely labeled through the left VF at the S1-S2 level (red) and anterogradely filled sacral afferents (cyan) labeled via the contralateral S3 dorsal root. $D$, The labeled VF neurons and afferents displayed in Care shown after VGluT1 immunostaining (yellow). E, $\boldsymbol{F}$, High-power (original magnification $X$ 60), single optical slice micrographs of the VF neurons in the area framed in $\boldsymbol{D}$ are shown in $\boldsymbol{E}$ and $\boldsymbol{F}$. $\boldsymbol{E}, \mathrm{V}$ neurons and afferents. $\boldsymbol{F}$, VF neurons contacted by primary afferent boutons IR for VGluT1 (yellow). Fluorophores: VF, cascade blue dextran (pseudo-color, red); afferents, Texas red dextran (pseudo-color, cyan); and VGluT1, Cy5.

Analyses of the data using the cross-Wavelet and Wavelet coherence algorithms revealed a significant increase in the coherent cross-power of the series produced by dual-branch stimulation, in which the motor output was maintained at much higher levels than in the control recordings obtained by high-intensity single-branch stimulation (Fig. 5C). Thus, it appears that lowintensity stimulation of presumed proprioceptive sacrocaudal afferents is a powerful modulator of the rhythm produced by activation of higher-threshold sacral afferents.
We performed 9 experiments in which we examined the capacity of low-intensity stimulation of contralateral dorsal root afferents (left and right Col or S4, 4 experiments), or afferents in an adjacent branch of the dorsal root (S4, Co1 or Co2, 5 experiments), to modulate the rhythm produced by stimulation of higher-threshold SCA. The proprioceptive conditioning in these experiments was done either by concurrent or short repetitive trains (similar effects). The rhythmic motor output produced by graded stimulation of SCA was augmented by proprioceptive conditioning in 7 of the 9 experiments. In two experiments, proprioceptive conditioning by the Col branch had no effect or resulted in reduced response. Thus, changes in the excitability of the sacral networks induced by activation of low-threshold afferent input have the ability to modulate the locomotor rhythm produced by higherthreshold input.

\section{Four different patterns of activity are exhibited by VF neurons during SCA stimulation}

After demonstrating glutamatergic innervation of VF neurons by SCA (Figs. 2, 3, 4 ), our next step was to determine whether sacral VF neurons are indeed activated by sacrocaudal afferents, and if so, whether the activity pattern, is related to the concurrent rhythmic output.

Figure 6 demonstrates the experimental strategy used in these combined imaging and electrophysiological studies using an example of a single VF neuron, backlabeled from cut VF axon bundles at the lumbosacral junction and imaged from the outer surface of the en bloc spinal cord preparation during the SCA-induced rhythm. The fluorescence emission was measured before (Fig. 6A1) and during (Fig. 6A2) SCA stimulation. Calcium transients were recorded as changes in the mean pixel intensity $(\Delta \mathrm{F})$ in the soma of the imaged neuron and in 10 regions of interest (ROIs) encircling the neuron (shown in Fig. 6A2), before and during the stimulus train, and expressed as the relative change in fluorescence $(\Delta \mathrm{F} / \mathrm{F}$, Fig. $6 B)$, where $\mathrm{F}$ is the mean prestimulus baseline (Fig. 6A3). The encircling ROIs were used to measure nonspecific (out-of-focus) fluorescence in the vicinity of the imaged neuron. The "specific" $\Delta \mathrm{F} / \mathrm{F}$ of the neuron (Fig. 6B3, blue) was obtained by subtracting the mean $\Delta \mathrm{F} / \mathrm{F}$ of the surrounding ROIs (Fig. $6 B 2$, red) from the $\Delta F / F$ of the neuron (Fig. 6B1,B2, black) during the stimulus train (O'Donovan et al., 1994). Then, the optical data were interpolated with the concurrently recorded motor output from the left and right L2 and S2 ventral roots (Fig. 6C1) and analyzed using the WT transformation algorithms (Fig. 6C2). The phase be- 
tween the optical and electrophysiological data was calculated from the spectral density plots of the coherent power obtained after omitting noncoherent regions from the cross-WT spectrum following a Monte Carlo-based WT coherence analyses (Mor and Lev-Tov, 2007; Etlin et al., 2010). The oscillatory optical component in the example shown in Figure $6 C 2$ was in phase with the motor output recorded from the side of the cord containing the imaged neuron (the right S2 and L2 ventral roots; i.e., contralateral to the filled VF axons; Fig. 6). Using this strategy and focusing our attention on individual rather than clusters of labeled VF neurons, we imaged the activity of 341 individual VF neurons of 621 labeled neurons (48 experiments, Fig. $7 A$ ), located at the sacral segments and visualized from different aspects of the cord surface. In some cases, the activity of VF neurons located within the deep gray matter was imaged from the dorsal aspect of the cord after removal of parts or of the entire dorsal horn (data not shown).

Figure 7, $B$ and $C$, shows few examples of the relative change in fluorescence of VF neurons imaged from the en bloc spinal cord preparation during low- and higher-intensity stimulus trains applied to the coccygeal dorsal roots. In one of these experiments (Fig. 7B), low-intensity stimulation of SCA produced a short fluorescence transient in the imaged neuron (left). However, when the stimulus intensity was increased from 2.5 to $10 \mu \mathrm{A}$, the cell exhibited an oscillatory drive that was in phase with the motor output recorded from the left lumbar and sacral ventral roots. In another experiment (Fig. 7C), 3 different VF neurons were imaged during 12 and $20 \mu \mathrm{A}$ stimulus trains. Note the diverse responses of these three neurons at the lower- and higher-stimulation intensities and the appearance of different patterns of activity when the rhythm was generated at the higher-stimulus intensity.

To evaluate the drive delivered by VF neurons to the lumbar networks during SCA stimulation, based on Wavelet analysis, we classified the responding VF neurons according to their activity patterns into a nonrhythmic and a rhythmic group. The nonrhythmic group included cells with monotonic (M) and irregular bursting (IB) activity patterns. The rhythmic group was subdivided into cells with rhythmic (R) pattern, and cells in which the oscillatory component was superimposed on a monotonic drive (RM). These four classes are shown in Figure 8A. Analysis of the activity patterns of the $322 \mathrm{VF}$ neurons that responded to SCA stimulation revealed $52.5 \%$ rhythmic (18\% R and $34.5 \%$ RM type) and 47.5\% nonrhythmic (41.3\% $\mathrm{M}$ and $6.2 \%$ IB type) VF neurons (Fig. 8B1).

Analyses of the relation between the oscillatory fluorescence changes and the
Table 1. Primary afferent glutamatergic innervation of $\mathrm{S} 2 \mathrm{VF}$ neurons with crossed rostral projections

\begin{tabular}{lcclrl}
\hline Lamina & VF cells & VF + Aff + VGluT1 & Lamina & VF cells & VF + Aff + VGluT2 \\
\hline IV, V & 65 & 11 & IV, V & 62 & 13 \\
VII, X & 247 & 51 & VII, X & 237 & 48 \\
VIII, IX & 63 & 5 & VIII, IX & 27 & 5 \\
Total number & 375 & 67 & Total number & 326 & 66 \\
\hline
\end{tabular}

The laminar distribution of S2 VF neurons contacted by sacral primary afferents with VGluT1 (VF + Aff + VGluT1) or VGluT2 (VF + Aff + VGluT2) immunoreactivity. Data are based on retrograde labeling of cut VF axon bundles at the lumbosacral junction, anterograde labeling of the contralateral sacrocaudal afferents entering the $\$ 2 / S 3$ dorsal root, and immunostaining for VGluT1 (2 experiments) orVGluT2 (4 experiments). Colocalization was determined only for VF neurons with clear putative SCA contacts using highpower confocal imaging (see Fig.4), and thus may underestimate the extent of innervation by VGluT IR primary afferents.
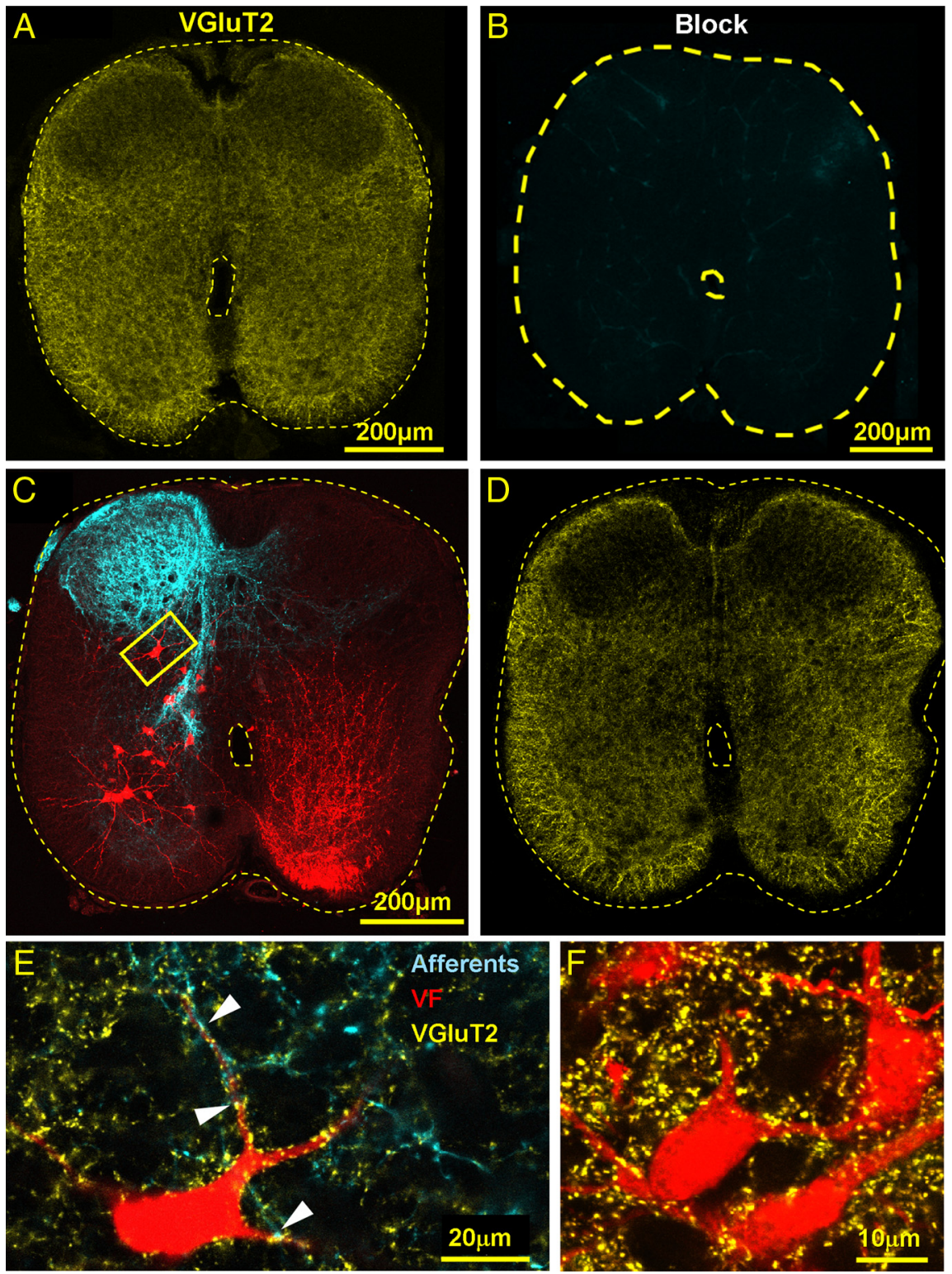

Figure 3. Primary afferent and intraspinal VGluT2IRinnervation ofVF neurons. $A, B$, The confocal micrograph in $A$ visualizes the specific immunostaining for VGluT2 (yellow) in a cross section through the $\mathrm{S} 2$ segment, which is completely abolished by pretreatment with the blocking peptide of the primary VGluT2 antibodies (B).C, Low-power projected confocal micrographs of a $50-\mu$ m cross section cut through the $S 2$ segment of the spinal cord shows VF neurons retrogradely labeled through the left VF at the S1-S2 level (red) and anterogradely filled sacral afferents (cyan) labeled via the contralateral (right) S3 dorsal root. D, The low-power cross section displayed in Cis shown after VGluT2 immunostaining (yellow). $\boldsymbol{E}$, High-power (original magnification $\times 60$ ), single-slice micrograph of the area framed in ( shows a VF neuron (pseudo color, red), which is contacted (e.g., arrowheads) by primary afferent boutons (pseudo color, cyan) with VGluT2 IR (yellow). Fluorophores: VF, Cascade blue dextran; Afferents, Texas red dextran; and VGluT2, Cy5.F, High-power (original magnification $\times 60$ ) view of a single optical slice micrograph of a group of $\mathrm{S} 2 \mathrm{VF}$ neurons back-labeled in a different double labeling experiment followed by immunostaining for VGluT2. The neurons are innervated by VGluT2 IR boutons but are not contacted by SCA. 
A
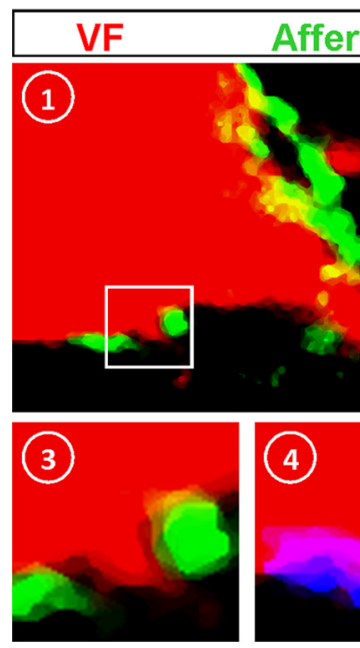
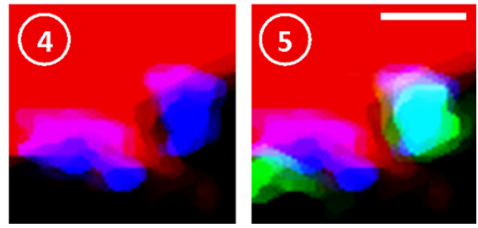

VGluT1

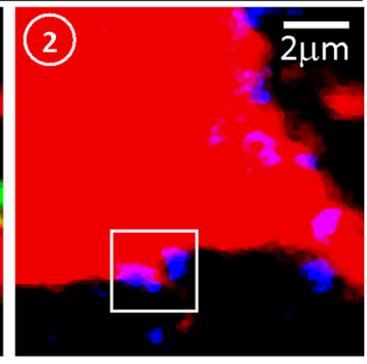

$2 \mu \mathrm{m}$

Figure 4. Primary afferent VGluT1 and VGluT2 innervation of VF neurons. A, B, Side-by-side display of single-slice high-power confocal micrographs of cross sections through $S 2$ (in two different experiments), showing putative VGluT1 $(\boldsymbol{A})$ and VGluT2 $(\boldsymbol{B})$ synaptic contacts between SCA and VF neurons. The sections are triple-labeled with fluorescent probes and shown in pseudo-colors: red, VF neuron; green, afferents; and blue, VGluTs. (1) Contacts of afferents with the VF neurons (yellow, merge of green on red). (2) Contacts of VGluTs with VF neurons (magenta, merge of blue on red). The magnified views taken from the regions confined within the squares in $\boldsymbol{A}$ and $\boldsymbol{B}$, respectively, are examples of the colocalizations of contacts on the VF neuron with the afferent ( 3 ), the VGluTs (4), and both (5, cyan). Optical slice thickness: $A, 0.76 ; \boldsymbol{B}, 1 \mu \mathrm{m}$. Scale bars, $1 \mu \mathrm{m}$.

rhythmic motor output were performed on the 169 (52.5\%) neurons belonging to the rhythmic group ( $\mathrm{R}$ and $\mathrm{RM}$ classes) of $\mathrm{VF}$ neurons (Figure $8 B 2$, histogram). Figure $8 C$ shows an example of the analysis of the relation between the activity of 2 of the imaged VF cells in one of the experiments and the concurrently recorded motor output (data shown in Fig. 8C1). Cross-WT analyses followed by coherence testing (Fig. 8C2) showed that the fluorescence changes in cell 1 (VF1) during SCA stimulation were in phase with the motor output recorded from the right S2 and L2 ventral roots, whereas the $\Delta \mathrm{F} / \mathrm{F}$ of cell 2 was in phase with the motor output recorded from the opposite side of the cord. Our results are summarized in Figure $8 D$. We found that the fluorescence oscillations of $73.3 \%$ of 161 contralaterally labeled VF cells belonging to the R-RM group (Fig. $8 D 1$ ) were in phase with motor output recorded ipsilaterally to their somata (mean phase shift $=14.6 \pm 29.3^{\circ}, \mathrm{r}$-vector $=0.88$, Rayleigh Test: $\left.p<0.001\right)$. The activity of the 8 ipsilaterally labeled VF neurons (Fig. 8D2) was also in phase with the ipsilateral motor output (mean phase shift $=13.2 \pm 20^{\circ}$, r-vector $=0.94$, Rayleigh Test: $p<0.001$ ). However, in $26.7 \%$ of the contralaterally labeled R-RM neurons, the fluorescence oscillations were in phase with the S2-L2 motor output on the opposite side of the cord to their somata (mean phase shift $=2.18 \pm 36.4^{\circ}$, r-vector $=0.82$, Rayleigh Test: $p<0.001)$.

\section{The contribution of VF neurons with tonic and rhythmic} activity patterns to activation of the thoracolumbar CPGs Selective pharmacological manipulations were performed to determine the source of rhythmic and nonrhythmic activity of sacral VF neurons during SCA stimulation and evaluate its relevance to the motor output. These experiments were performed on VF neurons with crossed lumbar projections. In the first series of experiments, we examined whether the oscillatory calcium transients of sacral VF neurons persisted after a selective block of the thoracolumbar rhythmicity. Bath application of the nonNMDA receptor antagonist CNQX to the thoracolumbar segments of the cord blocked the lumbar but failed to abolish either
B

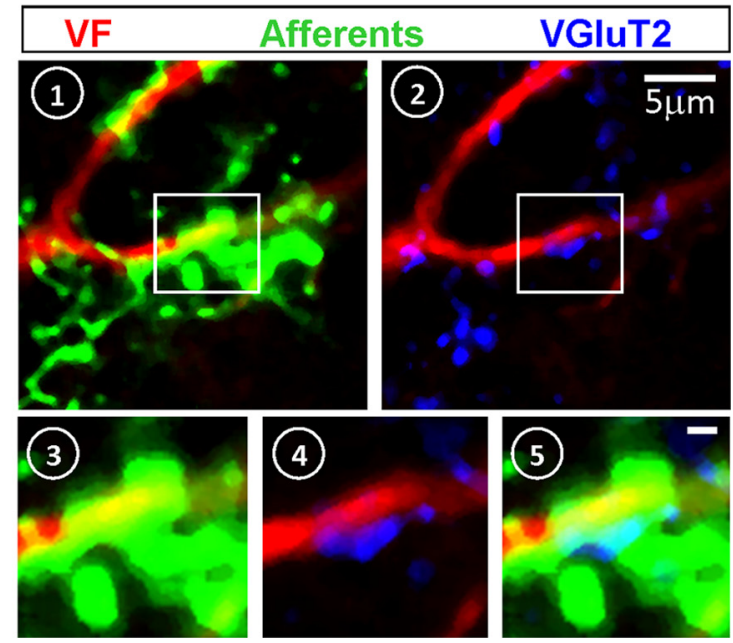

the sacrocaudal rhythmic output, or the oscillatory $\Delta \mathrm{F} / \mathrm{F}$ of the two sacral VF neurons imaged in this experiment (Fig. 9A). Similar results were observed for 5 additional VF neurons belonging to the rhythmic group ( 4 type $\mathrm{R}$ and 1 type $\mathrm{RM}$ ) imaged in 3 different experiments. The activity patterns of nonrhythmic VF neurons imaged in these experiments ( 3 type $\mathrm{M}, 1$ type IB) also persisted after addition of CNQX to the rostral compartment of the experimental bath, whereas the oscillatory drive of one of the RM type neurons was reduced. Thus, the rhythmic and nonrhythmic $\Delta \mathrm{F} / \mathrm{F}$ of VF neurons can be attributed mainly to activity of the sacrocaudal networks.

In contrast, when CNQX was added to the sacrocaudal segments of the spinal cord, the sacral rhythm was abolished together with the activity of all VF neurons, and SCA stimulation failed to activate the hindlimb pattern generators (Fig. 9B). Similar findings were observed in 7 experiments where the activity of 21 of 22 imaged neurons was completely abolished by sacral CNQX, and the activity of one of the neurons was severely attenuated but not completely blocked.

The experiments described above showed that the activity of VF neurons during SCA stimulation could be attributed to the functional non-NMDA receptor-mediated synaptic transmission in the sacral segments. However, it was not clear whether the activation of the VF neurons and thoracolumbar CPGs depended on activation of the rhythmogenic circuitry in the sacrocaudal segments. Strauss and Lev-Tov (2003) showed that it was possible to activate the lumbar CPGs by SCA stimulation when the sacrocaudal rhythm was blocked in the presence of the NMDA receptor antagonist APV in the sacral segments. Therefore, we next imaged the activity of VF neurons and recorded the lumbar motor output when the activity of the sacral CPGs was nearly blocked by APV. Indeed, bath application of the NMDA receptor antagonist APV $(20 \mu \mathrm{M}, 15 \mathrm{~min}$, Fig. 10A1) to the sacral compartment of the dual-chamber experimental bath nearly blocked the sacral rhythm and the rhythmic transients of the 3 imaged VF neurons (VF1-VF3), but did not affect the tonic change in fluorescence of the 3 neurons (Fig. 10A1, Caudal APV). The lumbar 
A
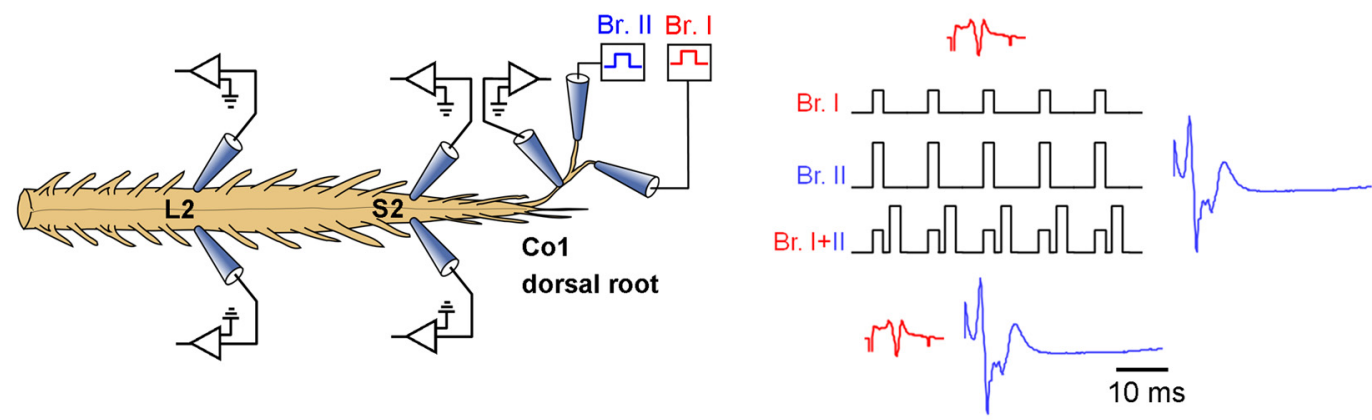

B
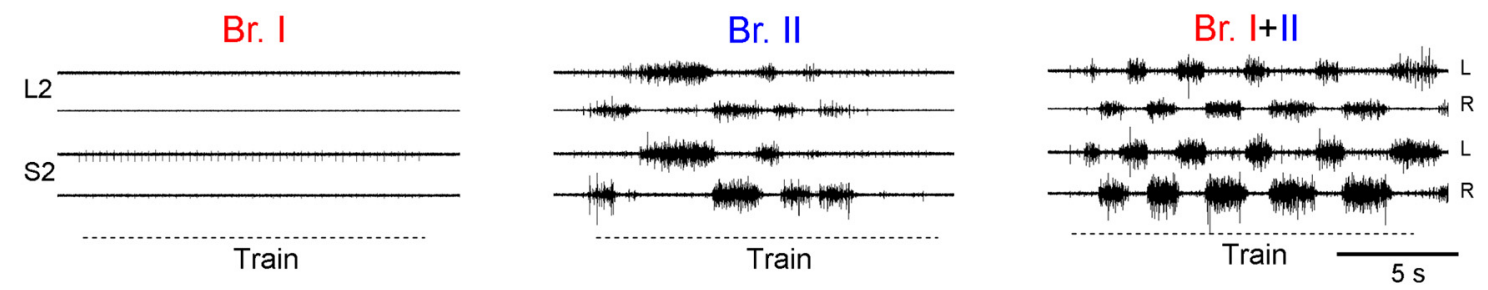

C

\section{Coherent power}
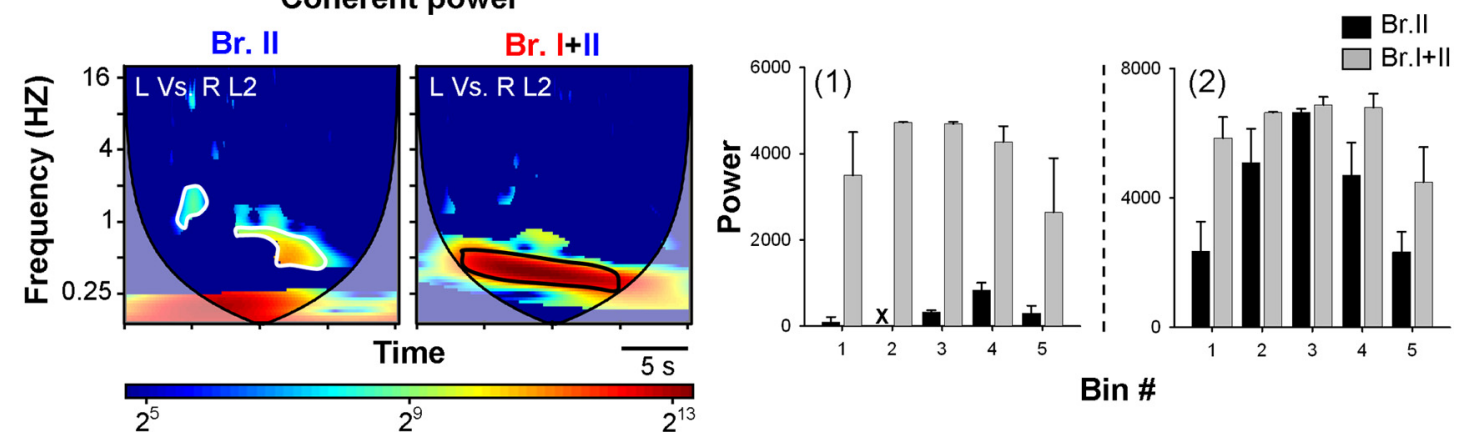

Figure 5. The rhythmic output produced by graded stimulation of higher-threshold SCA is modulated by the concurrently stimulated proprioceptive input. $\boldsymbol{A}$, Illustration of the experimental setup used in this series (left). The motor output recorded from the left and right ventral roots of $S 2$ and $\mathrm{L} 2$ is produced by stimulus trains delivered at different intensities to two branches of a split Co1 dorsal root while recording the incoming afferent volleys from the undivided proximal part of C 01 . Branch I is stimulated at Group I-II strength (red), whereas the stimulation of Branch II was set to exceed the threshold for activation of $A \delta$ fibers (blue). The two branches are stimulated separately or simultaneously (right scheme). $\boldsymbol{B}$, The motor output produced by stimulus train of Branch I at 3.6 $\mu \mathrm{A}$, Branch II at $9 \mu \mathrm{A}$, and both branches (Branch I + II) was recorded from the left and right ventral roots of S2 and L2; 50-pulse 3.3-Hz stimulus trains were applied in each case. C, Coherent cross-power density plots of the left versus right L2 time series obtained for the rhythm produced by Branch II and Branch I + II are shown on the left. The high-power frequency bands (delineated with white and black lines in the left and right spectra, respectively) were divided into 5 consecutive bins (Etlin et al., 2010) to extract the mean power of the conditioned (Branch I + II, gray bars) and the unconditioned (Branch II, black bars) responses as a function of time (C1). C2, Mean \pm SD of the power obtained in a different experiment performed under identical conditions, before (black) and after (gray) conditioning with proprioceptive afferents. Note the more moderate effect of proprioceptive conditioning on the motor output in this case. Two-way ANOVA followed by multiple-comparison tests using the modified Tukey's method revealed significant differences between the conditioned and unconditioned coherent power for each of the 5 bins in histogram $C 1$ $(p<0.007)$ and for the first and fifth bin in histogram $C 2(p<0.04)$.

rhythm produced under these conditions was not blocked. It persisted with a more moderate drive and regularity (Fig. 10A1, Caudal APV). These effects are demonstrated quantitatively in the histograms in Figure 10, A2 and A3. These histograms show the mean normalized power calculated from the coherent crosspower density plots of the activity produced in S2 and L2 before (black) and after (gray) addition of APV to the sacral segments (Fig. 10A2), and the mean normalized power calculated from the respective auto-WT spectra, describing the activity of the $3 \mathrm{im}-$ aged neurons under these conditions (Fig. 10A3). There was a substantial drop in the normalized coherent power of the sacral activity in the presence of APV, whereas the decrease in power of the lumbar activity was generally more moderate, especially toward the end of the stimulus train (compare the regions, marked as the third consecutive epoch, in Fig. 10A2 for the S2 and L2 histograms). At the same time, the rhythmic component of the activity of the 3 imaged neurons (Fig. 10A3) was virtually blocked throughout the stimulus train in one of the neurons (VF1) and during $66 \%$ of the train (first two epochs) in the two other cells (VF2 and VF3). A residual lower-power rhythmic activity appeared in these two cells only toward the end of the stimulus train (third epoch).

Analyses of the 30 imaged VF neurons in 7 experiments performed in this series revealed that the oscillations of the $\mathrm{R}$ type cells were blocked in 6 , and attenuated substantially in 4 of them. The oscillatory drive of the RM cells was blocked in 7 and diminished in 5 of them, without affecting the monotonic component. The 5 cells with monotonic activity (M) patterns remained active, 3 of them with a slightly reduced drive. Three of the imaged neurons belonged to the IB type. One of them was blocked, one was nearly blocked, and the other was unaffected by sacral APV.

In some of our experiments, we managed to demonstrate the differential consequences of blocking the non-NMDA and NMDA receptor-mediated synaptic transmission in the sacral 
A

(1)

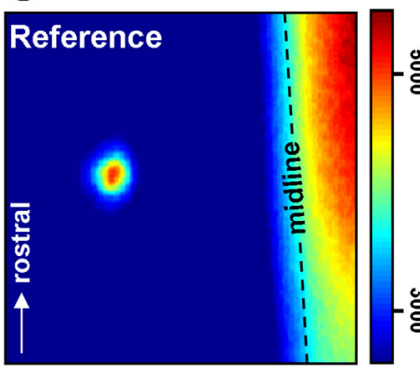

B

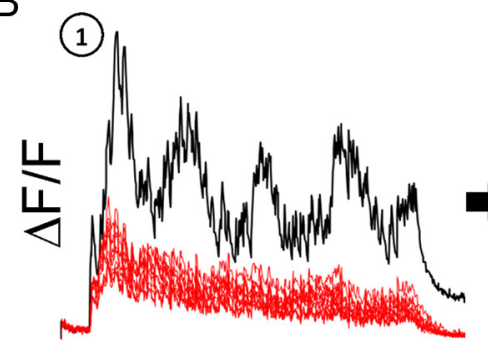

(2)

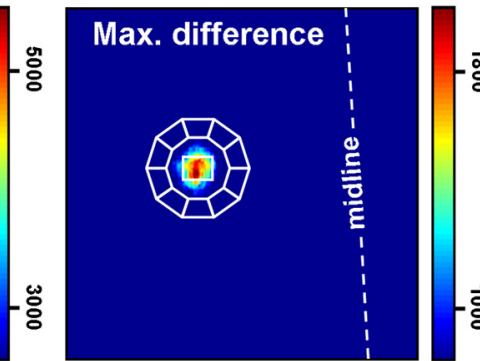

(2)

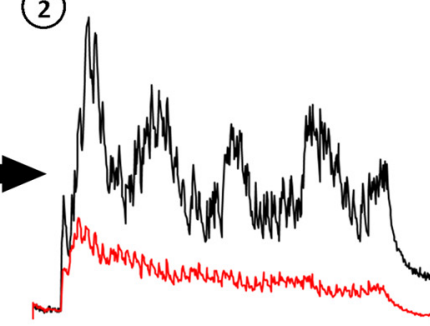

(3)

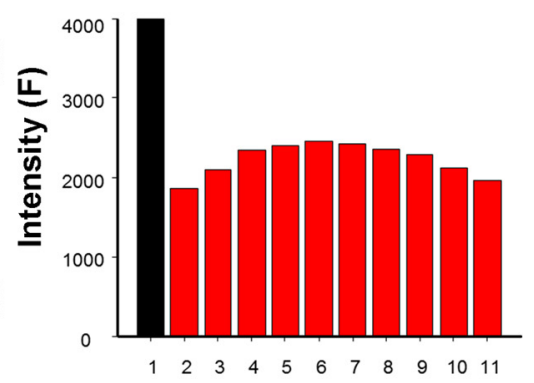

(3)

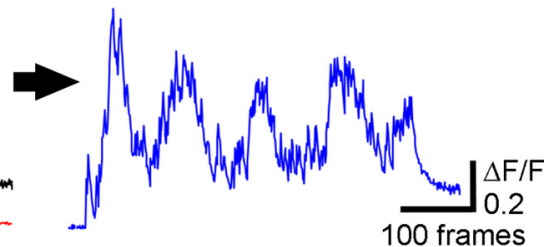

C
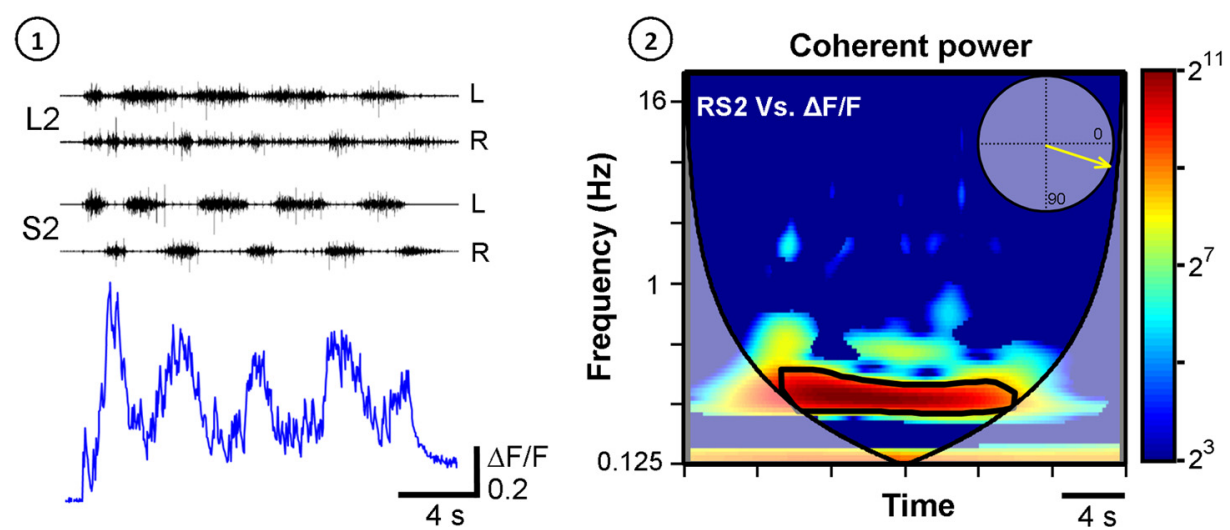

Figure 6. The activity of VF neurons and its correlation to the concurrent motor output are used to evaluate the involvement VF neurons in sensory activation of the CPGs. $A$, A single VF neuron, in the right $\$ 2$ segment, back-labeled with Calcium green dextran from cut VF axon bundles at the contralateral (left) lumbosacral junction and imaged from the ventral surface of the en bloc spinal cord, is shown before (A1, reference image) and during SCA stimulation ( $\boldsymbol{A} \mathbf{2}$, maximal difference image). The neuron is outlined by a white line and encircled by 10 regions of interest used to measure the out-of-focus fluorescence. The graph $(\boldsymbol{A} \mathbf{3})$ presents the mean pixel intensity of the neuron (black) and the encircling ROls (red) calculated from a five frame average taken before the stimulus train. Arrow indicates the rostral direction. $B$, The relative fluorescence changes $(\Delta \mathrm{F} / \mathrm{F}$ ) of the neuron (black) and the encircling $\mathrm{ROIs}$ (red) during the stimulus train are shown in $\boldsymbol{B} 1$. The specific $\Delta \mathrm{F} / \mathrm{F}$ of the neuron (blue, $\boldsymbol{B} 3$ ) was calculated by subtracting the mean $\Delta \mathrm{F} / \mathrm{F}$ of the encircling R0ls (red, $\boldsymbol{B 2}$ ) from that of the neuron (black, B2). $\boldsymbol{C}$, The rhythm produced by stimulation of the $\mathrm{C}$ 1 1 dorsal root and recorded from the left and right ventral roots of $S 2$ and $L 2$ is superimposed with the interpolated $\Delta F / F$ of the imaged neuron, as shown in $C 1$. The coherent cross-power density plot of the activity recorded from the right $\mathrm{S} 2$ ventral root versus the $\Delta \mathrm{F} / \mathrm{F}$ of the imaged neuron is shown in $\mathbf{C}$. The mean $\mathrm{R}$-vector in the circular inset plot, which was calculated from the high-power frequency band delineated by the black line, shows that both rhythms (right VF neuron and right $S 2$ ventral root) are in phase. Stimulation parameters: 40 -pulse 3 -Hz train applied at $9 \mu \mathrm{A}$. Imaging was at 27 $\mathrm{fps}$, the fluorescence excitation at $488 \mathrm{~nm}$, and emission measured at $530 \pm 15 \mathrm{~nm}$. This figure describes the strategy of the series of experiments combining fluorescence and electrical activity measurements.

segments on the same VF cells. One of these experiments is demonstrated in Figure 10B. Addition of APV to the sacral segments reduced the sacral motor output, virtually eliminated the oscillatory fluorescence changes of the imaged VF neuron, markedly reduced the sacrocaudal rhythmicity, and had a much lesser effect on the lumbar rhythmic output (Caudal APV). The "tonic" fluorescence changes of the imaged cell were unaffected or slightly augmented. The control pattern of the optical and electrophysiological signals (Control) reappeared after washing the APV for $35 \mathrm{~min}$ (APV wash) and were totally abolished $10 \mathrm{~min}$ after addition of the non-NMDA receptor blocker CNQX (10 $\mu \mathrm{M})$ to the sacral chamber (Caudal CNQX). This block could be alleviated after washing the CNQX for 60 min (CNQX wash). In summary, our dual-chamber pharmacological experiments sug- gest that nonrhythmic monotonic firing of VF neurons and lumbar rhythm can be generated when the sacrocaudal rhythmicity is nearly blocked, and that the rhythmic drive generated in sacral VF neurons when the sacral rhythm is produced during SCA stimulation augments the activation of the lumbar CPGs.

\section{Discussion}

Activation of the locomotor CPGs by SCA in the isolated spinal cord of the neonatal rat is mediated by a heterogeneous population of sacral relay neurons that project rostrally through the lateral and ventral white matter (Etlin et al., 2010). Here, we provide evidence for glutamatergic connectivity between sacral afferents and VF neurons and demonstrate the contribution of low- and high-threshold SCAs to activation of the hindlimb 
A

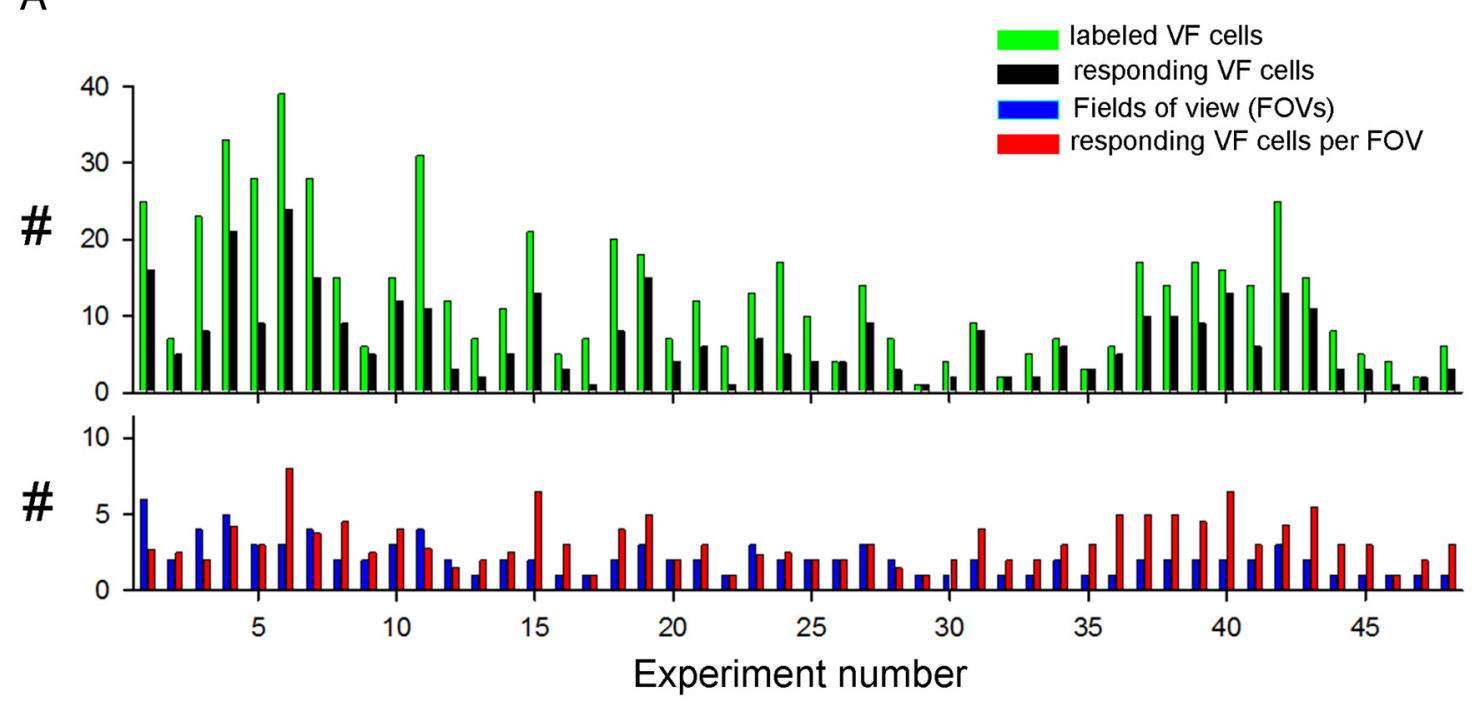

B
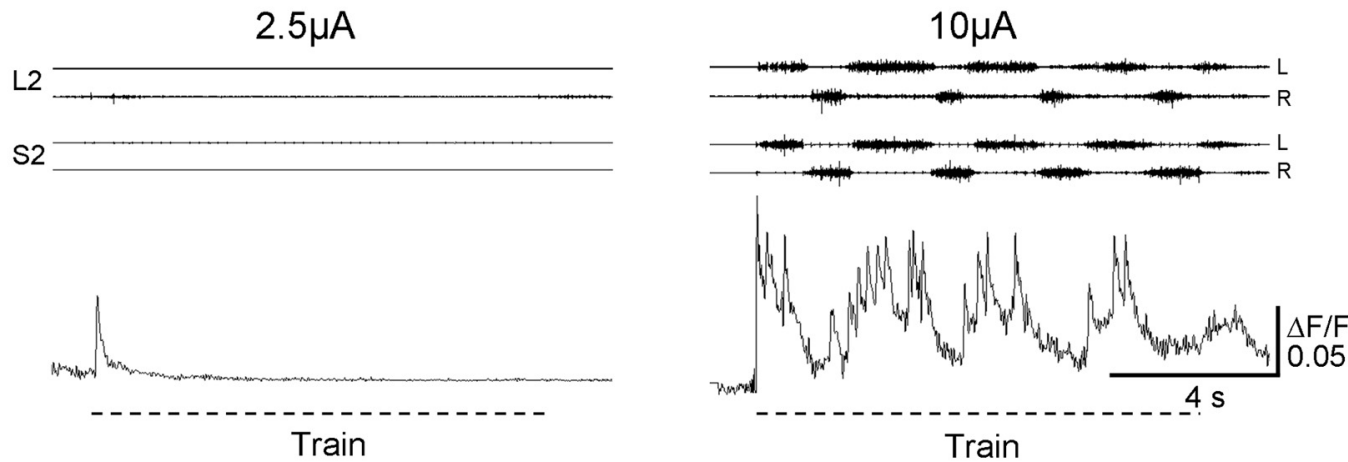

C

$12 \mu \mathrm{A}$

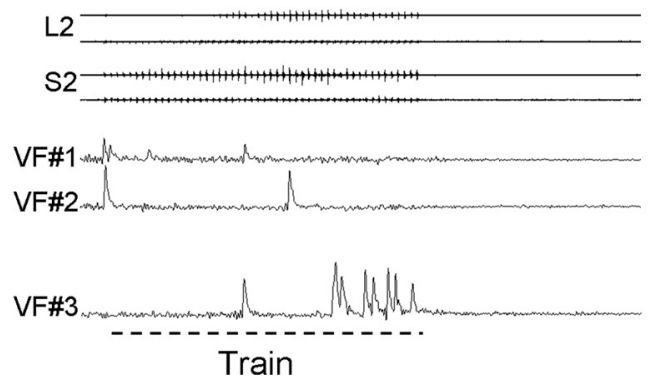

$20 \mu \mathrm{A}$

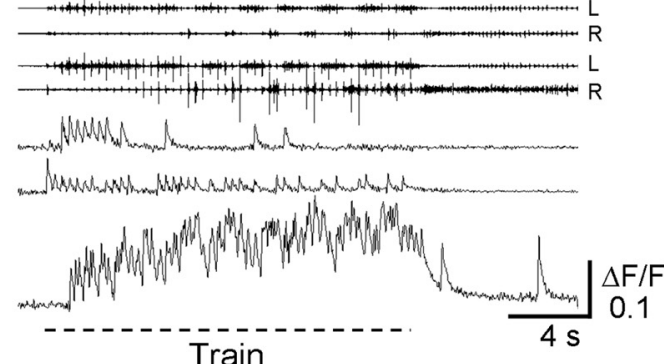

Train

Figure 7. Imaging of sacral VF neurons during low-intensity and higher-intensity SCA stimulation. A, Summary plot of the imaging experiments performed in the present work. Top histogram: Number of the labeled VF neurons (green) and of those responding to SCA stimulation (black) in each of the 48 experiments performed in this series. Bottom histogram: In each experiment, the number of the fields of view from which VF neurons were imaged (blue) and the number of responding VF neurons per field of view (red). $\boldsymbol{B}$, The activity pattern optically recorded from a left $S 2 \mathrm{VF}$ neuron back-labeled from the right VF during 50-pulse, 5 -Hz stimulus trains applied to the $\mathrm{C} 01$ dorsal root at 2.5 and $10 \mu \mathrm{A}$. The motor output was recorded simultaneously from the left and right ventral roots of $S 2$ and L2. C, The activity patterns of 3 different VF neurons at the leftS2 labeled through the right VF during 50-pulse, 3-Hzstimulus trains applied to the C 01 dorsal root at 12 and $20 \mu \mathrm{A}$. The motor output was recorded from the left and right ventral roots of $S 2$ and L2. Note the different activity patterns produced during the higher intensity stimulus trains in $\boldsymbol{B}$ and $\boldsymbol{C}$ and the low level activity during the lower-intensity stimulation.

CPGs. The activity pattern of VF neurons during SCA stimulation was determined using calcium imaging, and its contribution to the activity of the hindlimb CPGs was evaluated using Wavelet analysis.

Primary afferent and intraspinal glutamatergic innervation of VF neurons

Previously, we showed that the generation of the locomotor-like rhythm by SCA stimulation was abolished when the non-NMDA receptor blocker CNQX was applied to the sacral segments and that application of the NMDA receptor antagonist APV to the sacral segments virtually blocked the sacral but not the lumbar rhythm during SCA stimulation (Strauss and Lev-Tov, 2003). Thus, glutamatergic activation of sacral relay neurons is required for the generation of the locomotor rhythm by SCA stimulation. Here, we provide anatomical evidence for direct glutamatergic activation of sacral VF neurons by sacral afferent input. VGluT1 ${ }^{+}$ 
A

A Rhythmic (R)

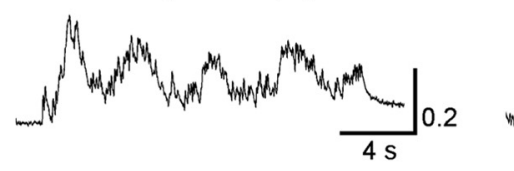

Monotonic (M)

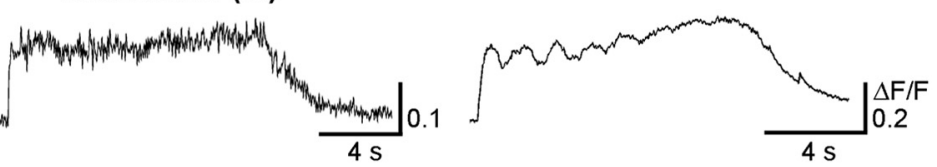

Irregular bursting (IB)

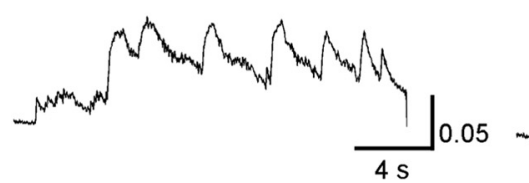

B

(1)

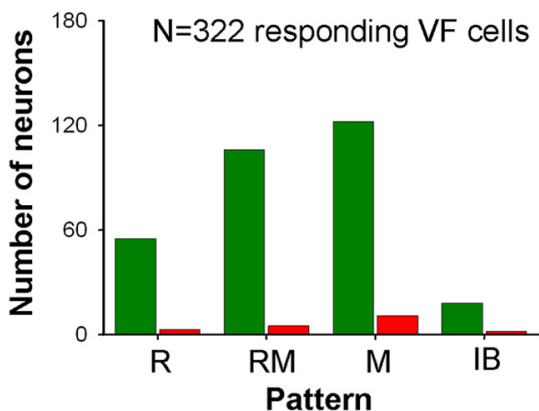

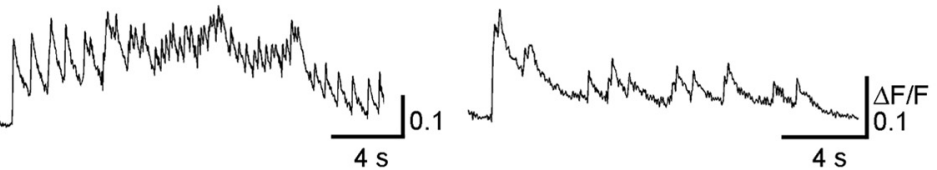

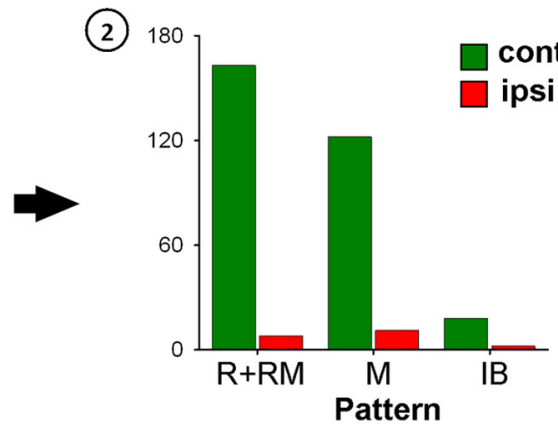

C

(1)

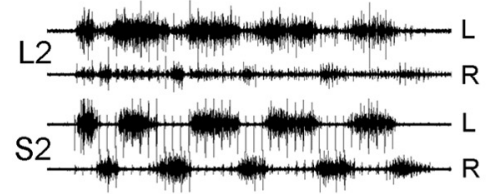

VF\#1 $N^{M}$

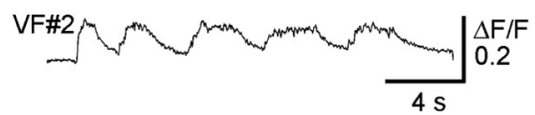

D
(1) $\mathrm{N}=161$ crossed VF neurons

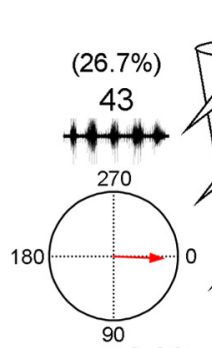

rvec $=0.82$

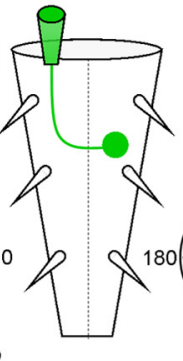

(1)
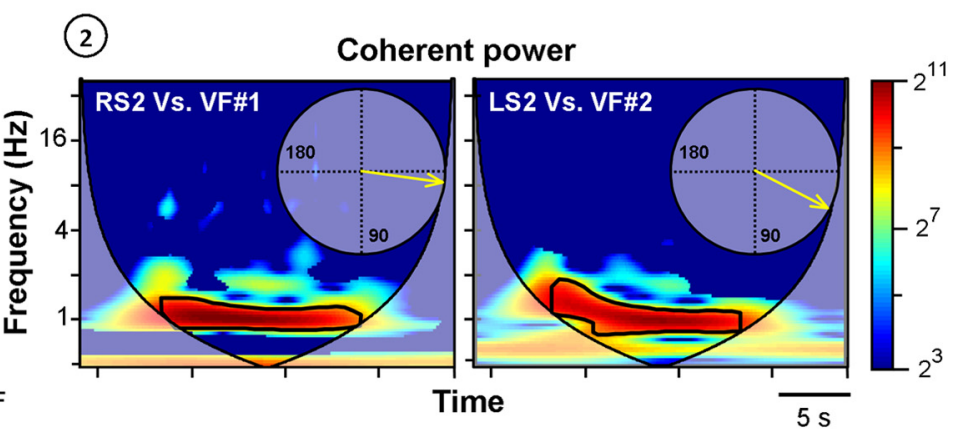

Figure 8. The activity patterns and phase preference of sacral VF neurons during SCA stimulation. $A$, Activity patterns of VF neurons $(\triangle F / F)$ during SCA stimulation. Top, bottom: VF cells with typical rhythmic (R), monotonic (M), monotonic with superimposed oscillations (RM), and irregular bursting (IB, 3 examples) patterns of activity. Stimulation parameters: Co1 dorsal root stimulation, R: 40-pulse 3-Hz train at $9 \mu$ A; M: 40-pulse 3.3-Hz train at $16 \mu \mathrm{A}$; RM: 30-pulse 3.3-Hz train at 12 $\mu$ A; IB (left): 40-pulse 2.5-Hz train at $10 \mu \mathrm{A}$; IB (middle): 60-pulse 4-Hz train at 30 $\mu \mathrm{A}$; IB (right): 40-pulse 2.5-Hz train at $12 \mu \mathrm{A}$. B. Distribution of the types of activity patterns exhibited by VF neurons labeled ipsilateral (red) or contralateral (green) to the injection site of the calcium sensor is shown before (B1) and after (B2) pooling the R and M group into a combined $R+$ RM group used for subsequent analyses of the phase preference of rhythmic VF neurons. $C$, Differential phase preference of VF neurons during SCA. Relative fluorescence changes in two VF neurons (VF1 and VF2) at the right S2 are shown with the concurrently recorded motor output from the left and right S2 and L2 ventral roots during SCA stimulation (C1). The coherent cross-power density spectra (C2) show that VF1 and VF2 were in phase with the right and left S2 activity, respectively. The high-power frequency bands of the two spectra are delineated with black lines, and the phase plots are shown in the respective insets (C2). Stimulus train: 40 pulse $3 \mathrm{~Hz}$ at $9 \mu \mathrm{A}$. The neurons were back-labeled through the right VF at the lumbosacral junction. $D$, An illustrated summary of the phase preferences of VF neurons that exhibit oscillatory drive ( $R+R M$ group) with crossed projections (D1) and uncrossed projections (D2). The circular plots show the phase with the motor output either ipsilateral or contralateral to the somata of the labeled VF neurons. 
A

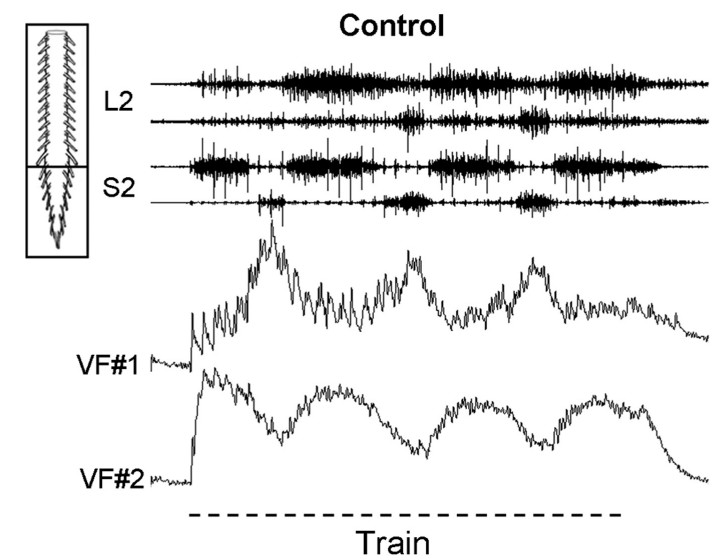

B

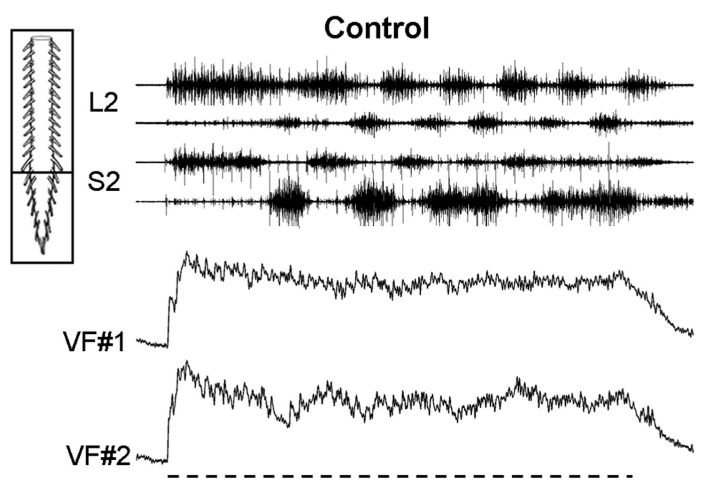

Train

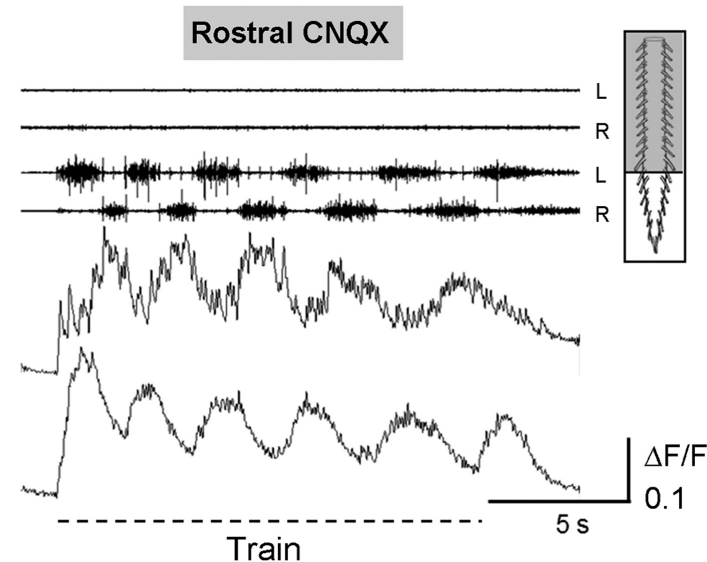

Train

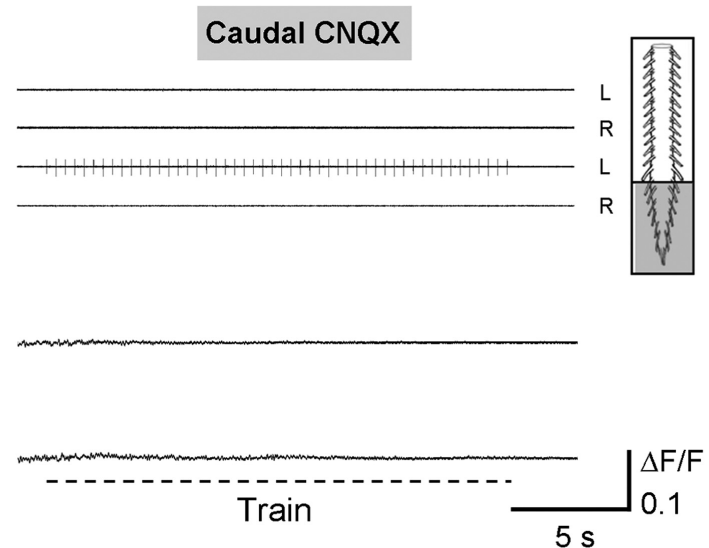

Figure 9. Activation of sacral VF neurons and the thoracolumbar CPGs depends on non-NMDA receptor-mediated synaptic transmission in the sacrocaudal segments of the cord. $\boldsymbol{A}$, The activity of sacral VF neurons during stimulation of the C01 dorsal root is shown with the motor output recorded from the left and right S2 and L2 ventral roots, before (Control) and 12 min after (Rostral CNQX) addition of the non-NMDA receptor antagonist CNQX (10 $\mu \mathrm{M})$ to the thoracolumbar compartments of a dual-chamber experimental bath. Stimulus train: 40 -pulse $2.5 \mathrm{~Hz}$ at $12 \mu \mathrm{A}$. $\boldsymbol{B}$, In a different experiment, similar recordings (as in $\boldsymbol{A}$ ) were done before (Control) and $8 \mathrm{~min}$ after (Caudal CNQX) bath application of CNQX to the sacrocaudal compartment. Stimulus train: 50 -pulse 2.5 Hz at 10 $\mu A$. Note the acceleration of the sacral rhythm and the oscillatory drive of the VF neurons as the lumbar rhythm was blocked $(\boldsymbol{A})$, and the total elimination of the activity of VF neurons, the sacral and lumbar activity when the sacral segments were exposed to $\operatorname{CNQX}(\boldsymbol{B}) . \boldsymbol{A}, \boldsymbol{B}$, The neurons are right-S2 neurons back-labeled from the contralateral VF at the lumbosacral junction.

or VGluT2 ${ }^{+}$primary afferent boutons were found to contact some of the sacral VF neurons. VGluT1 ${ }^{+}$synaptic boutons have been found on various types of spinal interneuron and tract neurons (Todd et al., 2003; Alvarez et al., 2004; Persson et al., 2006; Hantman and Jessell, 2010). Most VGluT1 ${ }^{+}$boutons express markers of cutaneous and muscle mechanoreceptors and disappear after dorsal rhizotomy (Alvarez et al., 2004). Therefore, we suggest that some of the sacral VF neurons receive proprioceptive innervation from sacrocaudal segments. Our finding that VF neurons received substantial VGluT2 ${ }^{+}$innervation from other intraspinal neurons is consistent with earlier work showing that many propriospinal interneurons are contacted by VGluT2 ${ }^{+}$terminals, the majority of which survive dorsal rhizotomy (Alvarez et al., 2004). During SCA stimulation, sacral VF neurons receiving VGluT2 ${ }^{+}$inputs may be activated by second-order sensory neurons or by other constituents of sacral networks, thereby participating in the successive recruitment of intraspinal neurons that has been postulated as one of the mechanisms responsible for activation of the locomotor CPGs during SCA stimulation (Etlin et al., 2010).

We do not know whether the VGluT2 ${ }^{+}$primary afferent connectivity we have described is unique to the sacral segments of the newborn rodent or whether it is preserved in the adult. However, because our experiments consistently showed VGluT2 ${ }^{+}$primary afferent connectivity with deep dorsal, lamina VII and, to a lesser extent, with some of the ventral laminae VF neurons, we suggest that, at least at this postnatal age, some sacral VF neurons can be activated directly, not only by VGluT1 ${ }^{+}$, but also by VGluT2 ${ }^{+}$ primary afferent contacts that may originate from paindelivering pathways (Alvarez et al., 2004; Liu et al., 2010; Scherrer et al., 2010; Rogoz et al., 2012).

\section{Proprioceptive modulation of the rhythm produced by graded SCA stimulation}

Proprioceptive hindlimb afferents (Group I and II) are known to modulate the locomotor rhythm in numerous vertebrate preparations and to control the timing and pattern of stepping (for review, see: McCrea, 2002; Pearson, 2004). In the present work, we showed that, although activation of sacral afferents by lowintensity stimulation (Group I-II strength) fails to produce the rhythm, it can effectively enhance the motor output produced by both low and higher-threshold afferents during stimulation at higher intensities. Thus, the rhythmic motor output of the hindlimb CPGs can be effectively modulated by proprioceptive sacral input. This latter finding is consistent with a recent report showing that the combination of rhythmic activation of sacral afferents and asynchronous input is the most potent means for generating the locomotor rhythm in the isolated spinal cord of 
A
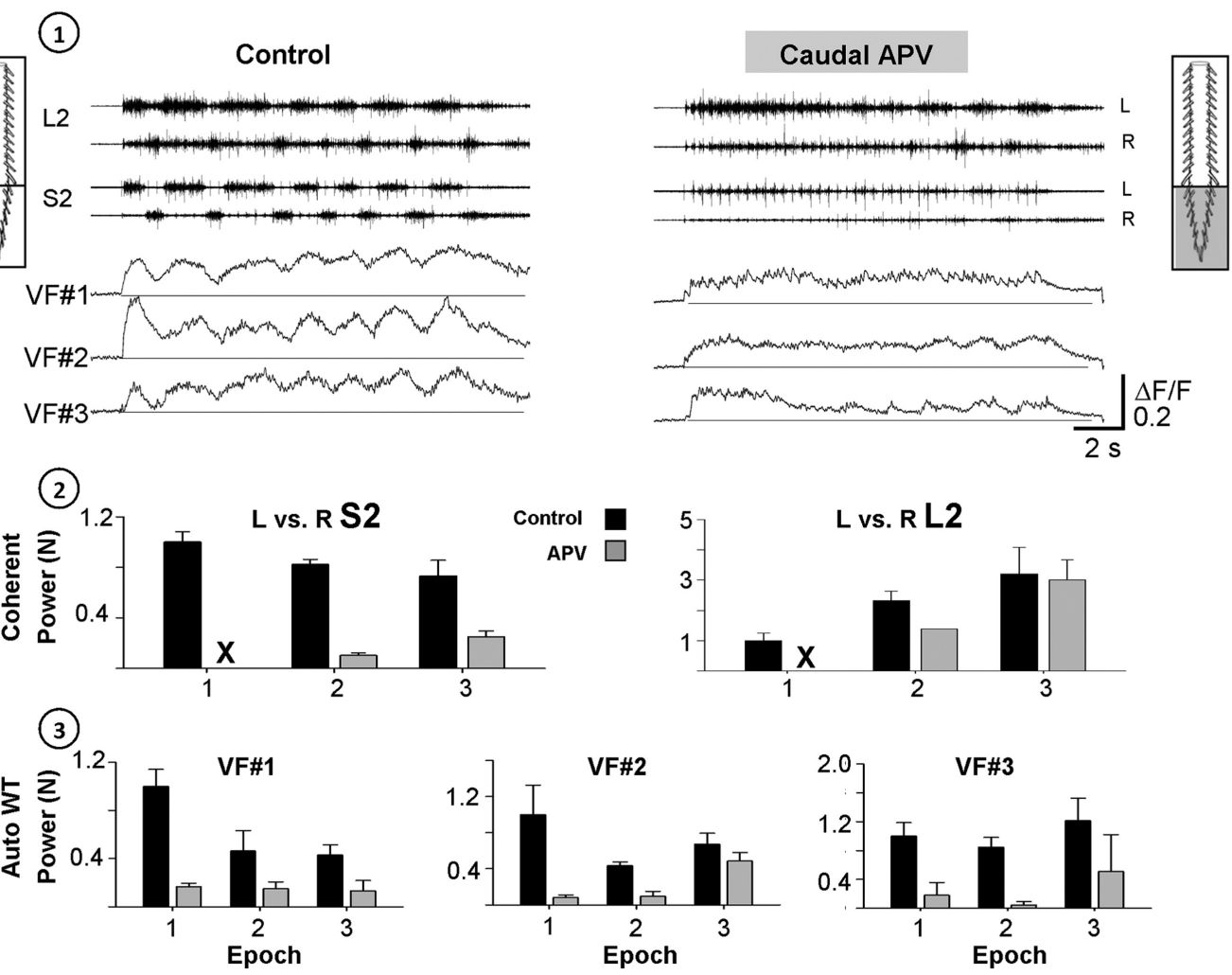

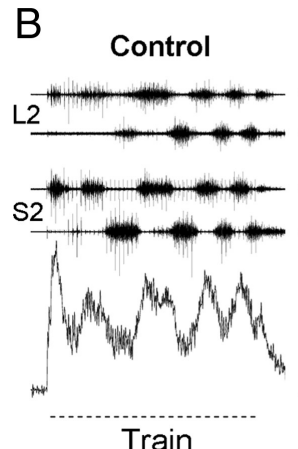

Train

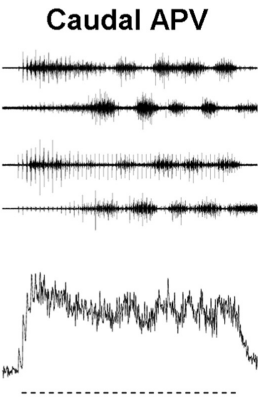

Wy

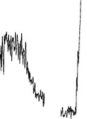

西

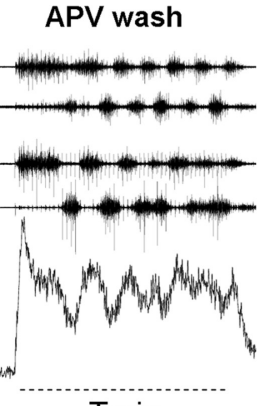

Train
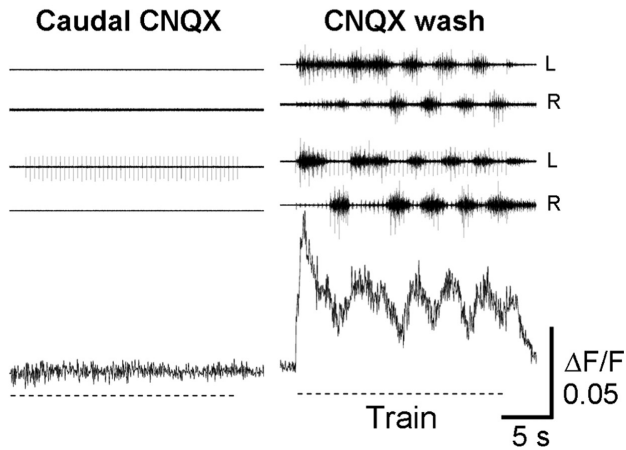

Figure 10. The involvement of rhythmic and nonrhythmic VF neurons and the sacral CPGs in sensory activation of the hindlimb CPGs. $A$, The activity of VF neurons and the motor output recorded from the left and right ventral roots of S2 and L2 during 40-pulse 5-Hz stimulus trains applied to the Co1 dorsal roots at $12 \mu \mathrm{A}$, are shown before (1; Control) and 15 min after (1; Caudal APV) application of the NMDA receptor antagonist APV $(20 \mu \mathrm{M})$ to the sacral segments in a dual-chamber experimental bath. The top 2 histograms $(\boldsymbol{A 2})$ show the normalized power of the motor rhythm (mean \pm SD), produced by SCA stimulation and recorded from the left and right ventral roots of $\mathrm{S} 2$ and $\mathrm{L} 2$ before ( $\mathbf{A 2}$; Control, black bars) and after addition of APV to the sacral compartment ( $\mathbf{A 2}$; APV, gray bars). The mean power for each pair of time series (Lvs RS2, and LvS RL2) was calculated at the beginning, middle, and end of the train (epochs 1, 2, and 3, respectively). A3, The mean \pm SD of the normalized auto-power of the $\Delta F / F$ of the 3 imaged neurons (VF 1,2, and 3) under these conditions. The normalized cross-power and auto-power values were calculated from the high-power frequency bands of the respective cross-power and auto-power density plots obtained by WT analyses after coherence test and $95 \%$ significance test of a $\chi^{2}$ power distribution, respectively (for further details, see Results). $\boldsymbol{B}$, The rhythmic activity from an RM-type VF neuron and the motor output recorded from the left and right $S 2$ and L2 ventral roots during stimulation of the Co1 dorsal root are shown before (Control), 20 min after addition of APV to the sacral segments (Caudal APV), 35 min after APV wash (APV wash), 10 min after addition of $10 \mu \mathrm{m}$ CNQX to the sacral segments (Caudal CNQX), and 60 min after CNQX wash (CNQX wash). Hyphenated lines indicate trains. Note that the rhythmic response of the VF cells is attenuated by APV, recovers when APV is washed, and all the activities are abolished by CNQX. Stimulation parameters: 50-pulse 2.5-Hz trains were applied at $10 \mu \mathrm{A}$. $\boldsymbol{A}, \boldsymbol{B}$, The neurons studied are right-S2 neurons back-labeled from the contralateral VF at the lumbosacral junction.

the neonatal rat by electrical stimulation of the cauda equina or SCA (Taccola, 2011).

\section{VF neurons and pattern generation}

Using calcium imaging, we showed that $55 \%$ of the labeled sacral VF neurons responded to graded electrical stimulation of SCA and that very little activity was exhibited by the VF neurons during low-intensity (Group I-II strength) stimulation. The neurons were activated in rhythmic ( $\mathrm{R}$ and RM) and nonrhythmic ( $\mathrm{M}$ and
IB) modes as the intensity of the stimulus train exceeded the threshold required for activation of the sacral and locomotor CPGs. Moreover, the activity of the rhythmic VF neurons ( $\mathrm{R}$ and RM) was in phase with the motor output recorded ipsilaterally and contralaterally to their somata in $73 \%$ and $27 \%$ of the cells, respectively. Our dual-chamber pharmacological experiments showed that the activity of rhythmic (R and RM type) and nonrhythmic ( $M$ and IB type) VF cells was blocked together with that of the sacral and lumbar rhythmogenic networks when the antag- 
onist CNQX was added to the sacral segments, and it persisted with the sacral rhythm when the lumbar segments were exposed to CNQX. Thus, the ability of SCA stimulation to activate the VF neurons and the CPGs depends on non-NMDA receptormediated synaptic transmission in the sacral segments. In addition, non-NMDA receptor-mediated synaptic transmission in the sacral segments was found to be the minimal prerequisite for activation of nonrhythmic VF neurons and the locomotor CPGs by SCA stimulation.

The ability of SCA stimulation to activate the lumbar CPGs when the sacral CPGs were nearly blocked by APV indicates that activity of the sacral CPGs is not required for activation of the lumbar CPGs by SCA stimulation. However, during SCA stimulation, activation of VF neurons and the locomotor CPGs was maximized when the sacrocaudal CPGs were also activated. This suggests that the discharge of VF neurons contributes causally to activation of the lumbar CPGs during SCA stimulation once the sacrocaudal rhythmogenic network has been activated. Collectively, these findings imply that the potency of SCA stimulation for locomotor CPGs activation is the result in part of activation of the body stabilizing sacral rhythmogenic network.

\section{The nature of the ascending drive delivered to the lumbar segments through the VF}

Etlin et al. (2010) showed that the drive produced by activation of sacral neurons in S2 and below was sufficient for activation of lumbar CPGs when synaptic transmission was blocked between rostral S2 and caudal L2. The S2 VF neurons studied in the present work were labeled at mid-L6 through their ascending projections so that their activity during SCA stimulation seems likely to have contributed to the ascending drive to the lumbar CPGs.

Unlike the thoracolumbar network, the reciprocal inhibition between flexor and extensor motoneurons in the sacrocaudal network is suppressed during the rhythm, and the two sacral hemicords define hypothetical half centers producing the alternating left-right excitation and crossed-inhibition responsible for the alternating rhythmic output (Lev-Tov and Delvolvé, 2000; Delvolvé et al., 2001). Therefore, it is tempting to suggest that the rhythmic VF neurons with contralateral phase preference may be linked to phasic excitation and those with ipsilateral phase preference are involved in activation of phasic inhibitory drive. Interestingly, studies of lumbar $\mathrm{V} 0$ commissural neurons in the mouse revealed that $70 \%$ of them were inhibitory and $30 \%$ were excitatory (Lanuza et al., 2004). Moreover, recent intracellular studies revealed that lamina VII GABAergic commissural neurons in the lumbar cord fired in phase with the motor output ipsilateral to their somata (Wu et al., 2011). These neurons have been suggested to produce rhythmic inhibition that is part of the hypothesized drive of the locomotor CPGs. Although plausible, the relation we suggest between the phase preference of VF neurons and the polarity of the ascending rhythmic drive remains hypothetical and must await further studies of the properties of the imaged VF neurons and their lumbar projections.

\section{Ascending pathways from sacral VF neurons, which may mediate sensory activation of CPGs}

The "direct" ascending pathways involved in activation of the CPGs may include long axonal projections of proprioneurons as well as spinal collaterals of tract neurons (Bras et al., 1988; Grottel et al., 1998; Dutton et al., 2006) projecting to the thalamus, reticular formation and cerebellum (Leah et al., 1988; Edgley and Grant, 1991; Yamada et al., 1991; Katter et al., 1996; Matsushita, 1998; Garifoli et al., 2006). The capacity of SCA input to produce locomotor activity in isolated rat spinal cords depends not only on the long ascending pathways, but also on recruitment of sacral proprioneurons interposed between the second-order neurons and the hindlimb CPGs (Etlin et al., 2010). Our results suggest that some of the VF neurons are innervated by sacral nociceptive afferents whose activation can produce the rhythm. These VF neurons and other second-order, sensory VF neurons associated with pain-delivering pathways may participate in activation of the locomotor CPGs (Etlin et al., 2010). However, VF neurons are only part of a heterogeneous population of sacral relay neurons, and more effort is required to clarify the mechanisms involved in this potent activation of the locomotor CPGs to pave the way for the development of novel ways for activating the locomotor CPGs in spinal cord injury patients.

\section{References}

Alvarez FJ, Villalba RM, Zerda R, Schneider SP (2004) Vesicular glutamate transporters in the spinal cord, with special reference to sensory primary afferent synapses. J Comp Neurol 472:257-280. CrossRef Medline

Arshavsky YI, Deliagina TG, Orlovsky GN (1997) Pattern generation. Curr Opin Neurobiol 7:781-789. CrossRef Medline

Blivis D, Mentis GZ, O'Donovan MJ, Lev-Tov A (2007) Differential effects of opioids on sacrocaudal afferent pathways and central pattern generators in the neonatal rat spinal cord. J Neurophysiol 97:2875-2886. CrossRef Medline

Bonnot A, Whelan PJ, Mentis GZ, O’Donovan MJ (2002) Spatiotemporal pattern of motoneuron activation in the rostral lumbar and the sacral segments during locomotor-like activity in the neonatal mouse spinal cord. J Neurosci 22:RC203. Medline

Bonnot A, Mentis GZ, Skoch J, O'Donovan MJ (2005) Electroporation loading of calcium-sensitive dyes into the CNS. J Neurophysiol 93:17931808. CrossRef Medline

Bras H, Cavallari P, Jankowska E (1988) Demonstration of initial axon collaterals of cells of origin of the ventral spinocerebellar tract in the cat. J Comp Neurol 273:584-592. CrossRef Medline

Delvolvé I, Gabbay H, Lev-Tov A (2001) The motor output and behavior produced by rhythmogenic sacrocaudal networks in spinal cords of neonatal rats. J Neurophysiol 85:2100-2110. Medline

Dietz V (2009) Body weight supported gait training: from laboratory to clinical setting. Brain Res Bull 78:I-VI. CrossRef Medline

Dietz V, Duysens J (2000) Significance of load receptor input during locomotion: a review. Gait Posture 11:102-110. CrossRef Medline

Dietz V, Wirz M, Jensen L (1997) Locomotion in patients with spinal cord injuries. Phys Ther 77:508-516. Medline

Dietz V, Müller R, Colombo G (2002) Locomotor activity in spinal man: significance of afferent input from joint and load receptors. Brain 125: 2626-2634. CrossRef Medline

Dutton RC, Carstens MI, Antognini JF, Carstens E (2006) Long ascending propriospinal projections from lumbosacral to upper cervical spinal cord in the rat. Brain Res 1119:76-85. CrossRef Medline

Duysens J, Pearson KG (1980) Inhibition of flexor burst generation by loading ankle extensor muscles in walking cats. Brain Res 187:321-332. CrossRef Medline

Edgerton VR, Kim SJ, Ichiyama RM, Gerasimenko YP, Roy RR (2006) Rehabilitative therapies after spinal cord injury. J Neurotrauma 23:560-570. CrossRef Medline

Edgerton VR, Courtine G, Gerasimenko YP, Lavrov I, Ichiyama RM, Fong AJ, Cai LL, Otoshi CK, Tillakaratne NJ, Burdick JW, Roy RR (2008) Training locomotor networks. Brain Res Rev 57:241-254. CrossRef Medline

Edgley SA, Grant GM (1991) Inputs to spinocerebellar tract neurones located in stilling's nucleus in the sacral segments of the rat spinal cord. J Comp Neurol 305:130-138. CrossRef Medline

Etlin A, Blivis D, Ben-Zwi M, Lev-Tov A (2010) Long and short multifunicular projections of sacral neurons are activated by sensory input to produce locomotor activity in the absence of supraspinal control. J Neurosci 30:10324-10336. CrossRef Medline

Etlin A, Mor Y, Finkel E, Anglister L, Lev-Tov A (2012) Imaging the activity in defined populations of funicular neurons during sensory activation of the locomotor rhythm in the mammalian spinal cord. J Mol Neurosci 48 [suppl 1]:S31. 
Finkel E, Etlin A, Lev-Tov A, Anglister L (2011) Anatomical evidence for the capacity of the sacral cholinergic system to increase discharge of lumbar motoneurons during sensory-induced locomotor like activity. J Mol Neurosci 45 [suppl 1]:S36.

Gabbay H, Lev-Tov A (2004) Alpha-1 adrenoceptor agonists generate a "fast" NMDA receptor-independent motor rhythm in the neonatal rat spinal cord. J Neurophysiol 92:997-1010. CrossRef Medline

Gabbay H, Delvolvé I, Lev-Tov A (2002) Pattern generation in caudallumbar and sacrococcygeal segments of the neonatal rat spinal cord. J Neurophysiol 88:732-739. Medline

Garifoli A, Maci T, Perciavalle V, Perciavalle V (2006) Organization of bilateral spinal projections to the lateral reticular nucleus of the rat. Arch Ital Biol 144:145-157. Medline

Gelfand IM, Orlovsky GM, Shik ML (1988) Locomotion and scratching in tetrapodes. In: Neural control of rhythmic movement in vertebrates (Cohen AH, Rossignol S, Grillner S (eds), pp 196-198. New York: Wiley.

Grillner S, Rossignol S (1978) On the initiation of the swing phase of locomotion in chronic spinal cats. Brain Res 146:269-277. CrossRef Medline

Grillner S, Zangger P (1979) On the central generation of locomotion in the low spinal cat. Exp Brain Res 34:241-261. CrossRef Medline

Grottel K, Krutki P, Mrówczyński W (1998) Triple projections of neurones located in S1 and S2 segments of the cat spinal cord to the C6 segment, the cerebellum and the reticular formation. Exp Physiol 83:737-746. Medline

Hantman AW, Jessell TM (2010) Clarke's column neurons as the focus of a corticospinal corollary circuit. Nat Neurosci 13:1233-1239. CrossRef Medline

Hultborn H, Conway BA, Gossard JP, Brownstone R, Fedirchuk B, Schomburg ED, Enríquez-Denton M, Perreault MC (1998) How do we approach the locomotor network in the mammalian spinal cord? Ann N Y Acad Sci 860:70-82. CrossRef Medline

Katter JT, Dado RJ, Kostarczyk E, Giesler GJ Jr (1996) Spinothalamic and spinohypothalamic tract neurons in the sacral spinal cord of rats. I. Locations of antidromically identified axons in the cervical cord and diencephalon. J Neurophysiol 75:2581-2605. Medline

Kiehn O (2006) Locomotor circuits in the mammalian spinal cord. Annu Rev Neurosci 29:279-306. CrossRef Medline

Klein DA, Tresch MC (2010) Specificity of intramuscular activation during rhythms produced by spinal patterning systems in the in vitro neonatal rat with hindlimb attached preparation. J Neurophysiol 104:2158-2168. CrossRef Medline

Kremer E, Lev-Tov A (1997) Localization of the spinal network associated with generation of hindlimb locomotion in the neonatal rat and organization of its transverse coupling system. J Neurophysiol 77:1155-1170. Medline

Lanuza GM, Gosgnach S, Pierani A, Jessell TM, Goulding M (2004) Genetic identification of spinal interneurons that coordinate left-right locomotor activity necessary for walking movements. Neuron 42:375-386. CrossRef Medline

Leah J, Menétrey D, de Pommery J (1988) Neuropeptides in long ascending spinal tract cells in the rat: evidence for parallel processing of ascending information. Neuroscience 24:195-207. CrossRef Medline

Lev-Tov A, Delvolvé I (2000) Pattern generation in non-limb moving segments of the mammalian spinal cord. Brain Res Bull 53:671-675. CrossRef Medline

Lev-Tov A, O’Donovan MJ (1995) Calcium imaging of motoneuron activity in the en-bloc spinal cord preparation of the neonatal rat. J Neurophysiol 74:1324-1334. Medline

Lev-Tov A, O’Donovan M (2009) Spinal cord: neonatal circuits. In: Encyclopedia of neuroscience (Squire LR, ed). Oxford: Academic.

Lev-Tov A, Delvolvé I, Kremer E (2000) Sacrocaudal afferents induce rhythmic efferent bursting in isolated spinal cords of neonatal rats. J Neurophysiol 83:888-894. Medline

Lev-Tov A, Etlin A, Blivis D (2010) Sensory-induced activation of pattern generators in the absence of supraspinal control. Ann N Y Acad Sci 1198: 54-62. CrossRef Medline

Liu Y, Abdel Samad O, Zhang L, Duan B, Tong Q, Lopes C, Ji RR, Lowell BB, Ma Q (2010) VGLUT2-dependent glutamate release from nociceptors is required to sense pain and suppress itch. Neuron 68:543-556. CrossRef Medline

Mandadi S, Whelan PJ (2009) A new method to study sensory modulation of locomotor networks by activation of thermosensitive cutaneous afferents using a hindlimb attached spinal cord preparation. J Neurosci Methods 182:255-259. CrossRef Medline

Matsushita M (1998) Ascending propriospinal afferents to area $\times$ (substantia grisea centralis) of the spinal cord in the rat. Exp Brain Res 119:356366. CrossRef Medline

McCrea D (2002) Sensory modulation of mammalian locomotor patterngenerating networks. J Physiol Lond 543:5S-5S.

Mentis GZ, Alvarez FJ, Bonnot A, Richards DS, Gonzalez-Forero D, Zerda R, O’Donovan MJ (2005) Noncholinergic excitatory actions of motoneurons in the neonatal mammalian spinal cord. Proc Natl Acad Sci U S A 102:7344-7349. CrossRef Medline

Mor Y, Lev-Tov A (2007) Analysis of rhythmic patterns produced by spinal neural networks. J Neurophysiol 98:2807-2817. CrossRef Medline

Mor Y, Etlin A, Shamir B, Zeilig G, Lev-Tov A (2011) Graphic processing unit (GPU)-based Wavelet analysis of rhythmic s-EMG data in spinal cord injury patients. J Mol Neurosci 45 [suppl 1]:S84.

Mor Y, Etlin A, Shamir B, Zeilig G, Lev-Tov A (2012) Graphic processing unit (GPU)-based Wavelet analysis of the rhythmic output produced by spinal pattern generators. J Mol Neurosci 48 [suppl 1]:S81.

O’Donovan MJ, Ho S, Sholomenko G, Yee W (1993) Real-time imaging of neurons retrogradely and anterogradely labelled with calcium-sensitive dyes. J Neurosci Methods 46:91-106. CrossRef Medline

O’Donovan M, Ho S, Yee W (1994) Calcium imaging of rhythmic network activity in the developing spinal cord of the chick embryo. J Neurosci 14:6354-6369. Medline

Pearson KG (2004) Generating the walking gait: role of sensory feedback. Prog Brain Res 143:123-129. CrossRef Medline

Persson S, Boulland JL, Aspling M, Larsson M, Fremeau RT Jr, Edwards RH, Storm-Mathisen J, Chaudhry FA, Broman J (2006) Distribution of vesicular glutamate transporters 1 and 2 in the rat spinal cord, with a note on the spinocervical tract. J Comp Neurol 497:683-701. CrossRef Medline

Prochazka A, Gillard D, Bennett DJ (1997) Positive force feedback control of muscles. J Neurophysiol 77:3226-3236. Medline

Rogoz K, Lagerström MC, Dufour S, Kullander K (2012) VGLUT2dependent glutamatergic transmission in primary afferents is required for intact nociception in both acute and persistent pain modalities. Pain 153: 1525-1536. CrossRef Medline

Rossignol S, Chau C, Brustein E, Belanger M, Barbeau H, Drew T (1996) Locomotor capacities after complete and partial lesions of the spinal cord. Acta Neurobiol Exp (Wars) 56:449-463.

Scherrer G, Low SA, Wang X, Zhang J, Yamanaka H, Urban R, Solorzano C Harper B, Hnasko TS, Edwards RH, Basbaum AI (2010) VGLUT2 expression in primary afferent neurons is essential for normal acute pain and injury-induced heat hypersensitivity. Proc Natl Acad Sci U S A 107: 22296-22301. CrossRef Medline

Strauss I, Lev-Tov A (2003) Neural pathways between sacrocaudal afferents and lumbar pattern generators in neonatal rats. J Neurophysiol 89:773784. CrossRef Medline

Taccola G (2011) The locomotor central pattern generator of the rat spinal cord in vitro is optimally activated by noisy dorsal root waveforms. J Neurophysiol 106:872-884. CrossRef Medline

Todd AJ, Hughes DI, Polgár E, Nagy GG, Mackie M, Ottersen OP, Maxwell DJ (2003) The expression of vesicular glutamate transporters VGLUT1 and VGLUT2 in neurochemically defined axonal populations in the rat spinal cord with emphasis on the dorsal horn. Eur J Neurosci 17:13-27. CrossRef Medline

Wernig A, Nanassy A, Müller S (1998) Maintenance of locomotor abilities following Laufband (treadmill) therapy in para- and tetraplegic persons: follow-up studies. Spinal Cord 36:744-749. CrossRef Medline

Wu L, Sonner PM, Titus DJ, Wiesner EP, Alvarez FJ, Ziskind-Conhaim L (2011) Properties of a distinct subpopulation of GABAergic commissural interneurons that are part of the locomotor circuitry in the neonatal spinal cord. J Neurosci 31:4821-4833. CrossRef Medline

Yamada J, Shirao K, Kitamura T, Sato H (1991) Trajectory of spinocerebellar fibers passing through the inferior and superior cerebellar peduncles in the rat spinal cord: a study using horseradish peroxidase with pedunculotomy. J Comp Neurol 304:147-160. CrossRef Medline

Zar J (1999) Biostatistical analysis, Ed 4. Upper Saddle River, NJ: Prentice Hall. 